\section{Pacific Northwest}

National Laboratory

Operated by Battelle for the

U.S. Department of Energy

\title{
Feasibility Study on Using Two Mixer Pumps for Tank 241-AY-102 Waste Mixing
}

Y. Onishi

B. E. Wells

August 2004

Prepared for the U.S. Department of Energy under Contract DE-AC06-76RL01830 


\section{DISCLAIMER}

This report was prepared as an account of work sponsored by an agency of the United States Government. Neither the United States Government nor any agency thereof, nor Battelle Memorial Institute nor any of their employees makes any warranty, express or implied, or assumes any legal liability or responsibility for the accuracy, completeness, or usefulness of any information, apparatus, product, or process disclosed or represents that its use would not infringe

privately owned rights. Reference herein to any specific commercial product, process, or service by trade name, trademark, manufacturer, or otherwise does not necessarily constitute or imply its endorsement, recommendation, or favoring by the United States Government or any agency thereof, or Battelle Memorial Institute. The views and opinions of authors expressed herein do not necessarily state or reflect those of the United States Government or any agency thereof.

\section{PACIFIC NORTHWEST NATIONAL LABORATORY operated by \\ BATTELLE \\ for the UNITED STATES DEPARTMENT OF ENERGY under Contract DE-AC06-76RL01830}

Printed in the United States of America Available to DOE and DOE contractors from the Office of Scientific and Technical Information, P.O. Box 62, Oak Ridge, TN 37831-0062;

ph: (865) 576-8401

fax: (865) 576-5728

email: reports@adonis.osti.gov

Available to the public from the National Technical Information Service, U.S. Department of Commerce, 5285 Port Royal Rd., Springfield, VA 22161 ph: (800) 553-6847 fax: (703) 605-6900 email: orders@ntis.fedworld.gov online ordering: http://www.ntis.gov/ordering.htm

This document was printed on recycled paper. 


\title{
Feasibility Study on Using Two Mixer Pumps for Tank 241-AY-102 Waste Mixing
}

\author{
Y. Onishi \\ B. E. Wells
}

August 2004

\author{
Prepared for \\ the U.S. Department of Energy \\ under Contract DE-AC06-76RL01830
}

Pacific Northwest National Laboratory

Richland, WA 99352 


\section{Executive Summary}

The current waste retrieval plan for Hanford double-shell Tank 241-AY-102 (AY-102) calls for using two mixer pumps to mix the waste stored within it. The objective of this evaluation was to determine whether two rotating 300-hp pumps located $22 \mathrm{ft}(6.7 \mathrm{~m})$ from the center of the tank could adequately mix the AY-102 waste.

The tank now contains 248 in. $(6.3 \mathrm{~m})$ of high-level radioactive waste consisting of 62 in. $(1.58 \mathrm{~m})$ of sludge and 186 in. $(4.72 \mathrm{~m})$ of supernatant liquid. Based on the available data, AY-102 waste properties were determined, including the densities of the liquid and the mostly agglomerated settled (bulk) solids (the sludge) and solid particles, the solid volume fraction in the settled solids, the solid particle size distribution, the liquid and slurry viscosities, and the yield stress in shear (shear strength) of the settled solids layer.

To evaluate the likely and bounding cases of AY-102 waste mixing, sludge erosion modeling was performed with a median value of 1,090 $\mathrm{Pa}$ (likely condition) and a conservative (more difficult to erode) 97.5 percentile value of 2,230 $\mathrm{Pa}$ for shear strength. According to the AY-102 model predictions, the two rotating mixer pumps would erode $89 \%$ of the sludge that has a shear strength of $1,090 \mathrm{~Pa}$ up to $41 \mathrm{ft}$ $(12.5 \mathrm{~m})$ away from the mixer pumps. However, due to the tank wall effect, they would not mobilize the sludge next to the tank wall, which is more than $26 \mathrm{ft}(7.9 \mathrm{~m})$ from the pumps. Moreover, the pumps would not mobilize the bottom 2.5 in. $(0.06 \mathrm{~m})$ of sludge. Once the sludge was mobilized, the solids were predicted to be uniformly suspended within the tank within a 1-vol\% concentration variation $(99 \%$ uniformity), except those within few inches of the bottom.

The two pumps would erode $85 \%$ of the sludge with a shear strength of $2,230 \mathrm{~Pa}$, slightly less than the $89 \%$ in the $1,090-\mathrm{Pa}$ shear strength case. In this case, the pump jets would mobilize sludge up to $38 \mathrm{ft}$ $(11.6 \mathrm{~m})$ away from the pumps. Like the 1,090-Pa shear strength case, the mixer pumps would leave the sludge at the tank wall that is $20 \mathrm{ft}(6.1 \mathrm{~m})$ or farther from the pumps due to the wall effect. The model predicts that the bottom 2.5 in. $(0.06 \mathrm{~m})$ of sludge remains. Similar to the 1,090-Pa shear strength case, the solids were predicted to be uniformly suspended except within a few inches of the tank bottom. These results indicate that the greater the sludge shear strength, the less the mixer pumps can erode, although the differences are small between the 1,090 and 2,230 Pa cases in erosion amount and maximum erosion distance from the pumps. 


\section{Contents}

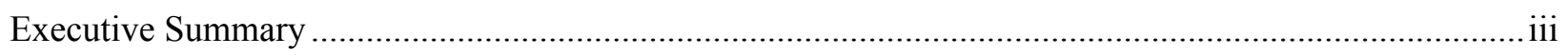

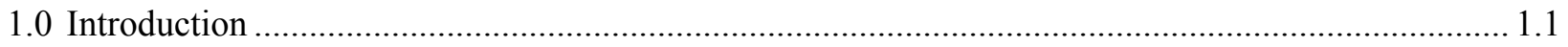

2.0 Specific Waste Properties for Tank 241-AY-102 ...................................................................... 2.1

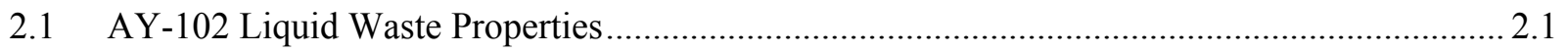

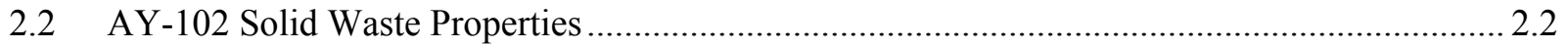

2.2.1 Settled Solids Layer Depth, Density, and Solid Volume Fraction ...................................... 2.2

2.2.2 Settled Solids Layer Particle Size ............................................................................. 2.3

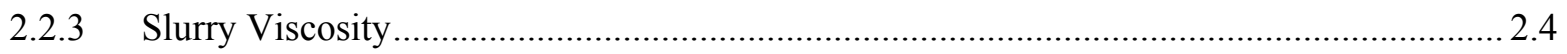

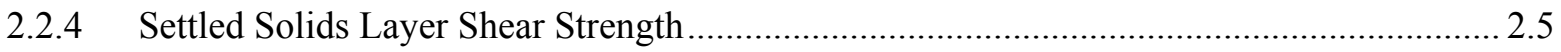

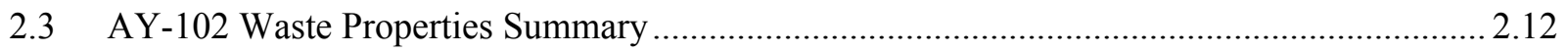

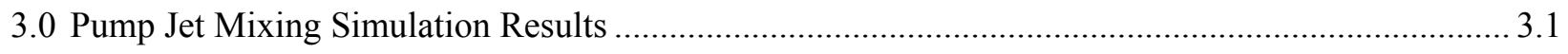

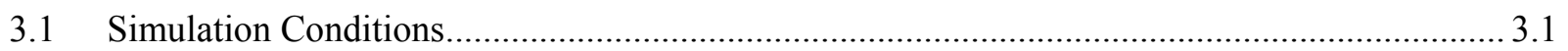

3.2 Pump Jet Mixing of AY-102 Waste with 1,090-Pa Shear Strength.......................................... 3.3

3.3 Pump jet Mixing of AY-102 Waste with 2,230-Pa Shear Strength ........................................ 3.8

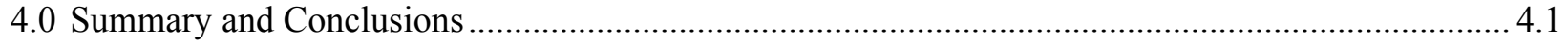

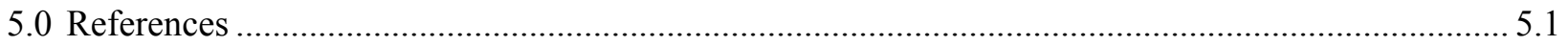




\section{Figures}

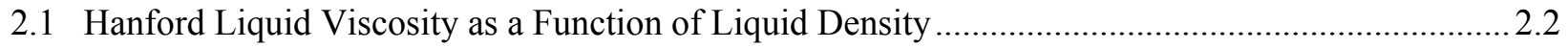

2.2 AY-102 Slurry Viscosity as a Function of the Solids Volume Fraction.........................................2.5

2.3 AY-102 Horizontal Core Extrusion Failure Length (Core 270) ...................................................... 2.6

2.4 AY-102 Horizontal Core Extrusion Failure Length (Core 290) ....................................................2.7

2.5 Shear Strength of AY-102 Settled Solids Layer Estimated from Waste Core Extrusions .................2.9

2.6 Shear Strength of AY-102 Settled Solids Layer: Extrusion Length and Shear Vane Results ........2.10

2.7 Shear Strength of AY-102 Settled Solids Layer: Extrusion Length and Shear Vane

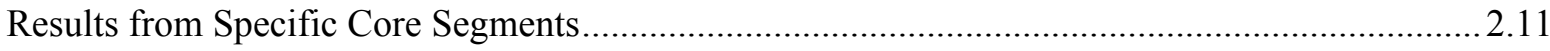

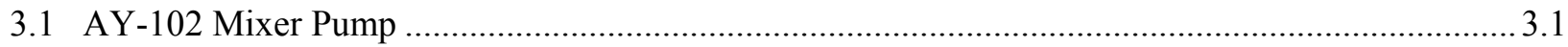

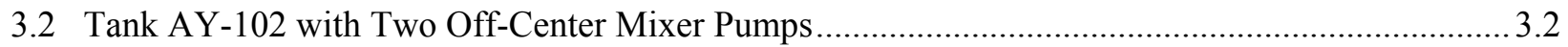

3.3 Initial AY-102 Waste Condition along 3 O'Clock Position (vertical plane 2) ................................ 3.3

3.4 Initial AY-102 Waste Condition along 12 O'Clock Position (vertical plane 14) ............................. 3.4

3.5 Tank Area Eroded by the Two Mixer Pumps for the 1,090-Pa Shear Strength Case ........................ 3.5

3.6 Predicted Distributions of Velocity and Sludge Erosion with 1,090-Pa Shear Strength along the Shortest Distance to the Tank Wall at 2 Simulation Hours ............................................... 3.6

3.7 Predicted Distributions of Velocity and Sludge Erosion with 1,090-Pa Shear Strength along 1:40 O'Clock Position to Tank Wall at 2 Simulation Hours................................................... 3.7

3.8 Predicted Distributions of Velocity and Sludge Erosion with 1,090-Pa Shear Strength along 12:25 O'Clock Position to the Tank Wall at 2 Simulation Hours.......................................... 3.7

3.9 Predicted Distributions of Velocity and Sludge Erosion with 1,090-Pa Shear Strength along Longest Distance to Tank Wall at 2 Simulation Hours......................................................... 3.8

3.10 Tank Area Eroded by Two Mixer Pumps for the 2,230-Pa Shear Strength Case ............................3.9

3.11 Predicted Distributions of Velocity and Sludge Erosion with 2,230-Pa Shear Strength along the Shortest Distance to the Tank Wall at 2 Simulation Hours............................................. 3.10

3.12 Predicted Distributions of Velocity and Sludge Erosion with 2,230-Pa Shear Strength along 1:40 O'Clock Position to Tank Wall at 2 Simulation Hours.................................................10

3.13 Predicted Distributions of Velocity and Sludge Erosion with 2,230-Pa Shear Strength along 1:25 O'Clock Position to Tank Wall at 2 Simulation Hours.

3.14 Predicted Distributions of Velocity and Sludge Erosion with 2,230-Pa Shear Strength along the Longest Distance to Tank Wall at 2 Simulation Hours 


\section{Tables}

2.1 Volume Particle Size Distribution for AY-102 _................................................................... 2.4

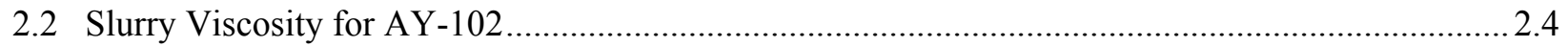

2.3 AY-102 Extrusion Length Shear Strength Results .................................................................. 2.8

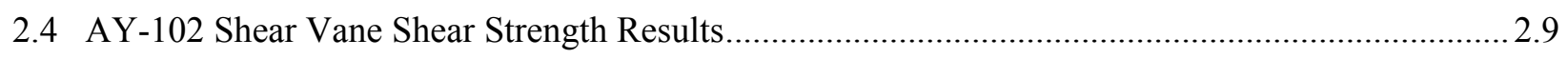

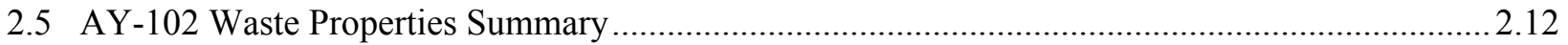

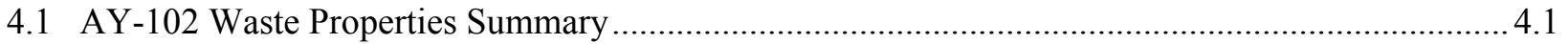




\subsection{Introduction}

The current waste retrieval plan for Hanford Tank 241-AY-102 (AN-102) calls for mixing the waste stored within it using two mixer pumps located $22 \mathrm{ft}(6.7 \mathrm{~m})$ from the tank center. The objective of this evaluation was to determine whether two rotating 300-hp mixer pumps would adequately mix the AY-102 tank waste. Four mixer pumps would be an option if two pumps were not sufficient.

Tank AY-102 is located in the AY tank farm in the 200 East Area on the U.S. Department of Energy's Hanford Site in southeastern Washington State. It is one of 28 double-shell tanks (DSTs) storing radioactive waste at Hanford. The tank contains 248 in. $(6.3 \mathrm{~m})$ of high level radioactive waste (HLW) consisting of 62 in. $(1.58 \mathrm{~m})$ of sludge and 186 in. $(4.72 \mathrm{~m})$ of supernatant liquid (Baker and Hedengren 2003).

To determine whether two pumps are sufficient to mobilize the AY-102 sludge and mix it well with the overlying supernatant liquid, we performed the following tasks:

- Determined AY-102 waste properties

- Simulated AY-102 sludge erosion and mixing by two $300 \mathrm{hp}$ off-center pumps

- Assessed the feasibility of using two mixer pumps to mix the sludge and supernatant liquid as part of the AY-102 waste retrieval operations.

The AY-102 waste properties evaluated in this study include the density of the liquid waste and mostly agglomerated settled (bulk) solids (the sludge consisting of solids and interstitial solution) and solid particles, the solid volume fraction in the settled solids, the solids particle size distribution, the liquid and slurry viscosities, and the yield stress in shear (shear strength) of the settled solids layer. Bestestimate values for these waste properties were determined based on the available data. The shear strength of the AY-102 waste is the key waste property that affects the ability of the pump jets to erode the sludge. Shear strength was determined using a core extrusion estimation technique (Rassat et al. 2003) and previously measured shear vane values. Because the shear strength values estimated by video observation of AY-102 core extrusion were generally larger, more consistent, and more in line with similar Hanford tank wastes than the shear vane values, we used these estimates for our simulations.

We used the time-varying, three-dimensional, computational fluid dynamics code, TEMPEST (Onishi and Trent 1999), to simulate sludge erosion and subsequent mixing of the mobilized sludge and supernatant liquid in Tank AY-102. To evaluate the likely and bounding cases of the AY-102 waste

mixing, the AY-102 modeling was performed with the median value (likely condition) and a conservative (more difficult to erode) 97.5 percentile value for the shear strength.

Section 2 describes AY-102 tank waste properties. Section 3 presents the results of AY-102 sludge erosion and mixing modeling. The summary and conclusions are stated in Section 4, and cited references are listed in Section 5. 


\subsection{Specific Waste Properties for Tank 241-AY-102}

DST AY-102 has a $37.5 \mathrm{ft}$ radius and an operating capacity of one-million gallons. The waste stored in AY-102 consists of a liquid layer overlaying a settled solid (sludge) layer. Specific AY-102 waste properties are required as inputs to the TEMPEST code to model waste mixing.

The waste properties include the depths of the liquid and settled solid layers; the densities of the liquid, settled solids (sludge), and undissolved solids; the solid volume fraction in the settled solids; the solids particle size distribution; the viscosities of the liquid and slurry; and the yield stress in shear (shear strength) of the settled solids layer. Best-estimate values for these waste properties were determined based on the available data. In Section 2.1, liquid waste properties are presented; in Section 2.2 the properties of the settled solids are discussed. The waste properties are summarized in Section 2.3.

\subsection{AY-102 Liquid Waste Properties}

The supernatant liquid in AY-102 is approximately 186 in. $(4.72 \mathrm{~m})$ deep and has a density of $1,150 \mathrm{~kg} / \mathrm{m}^{3}$ (TWINS; Barker and Hedengren 2003). Warrant (2001) reported that the viscosity measurements of AY-102 waste feed delivery samples gave evidence of Newtonian behavior. With Newtonian fluids, the viscosity is independent of the shear rate, and the measured shear stress may be expressed as a function of the shear rate by

$$
\tau=\mu \gamma
$$

where $\tau$ is the shear stress $(\mathrm{Pa}), \mu$ is the viscosity $(\mathrm{Pa} \mathrm{s})$, and $\gamma$ is the shear rate $\left(\mathrm{s}^{-1}\right)$.

Based on the data of Warrant (2001) and using Eq. (2.1), the viscosity of the liquid samples ranged from $0.0035 \mathrm{~Pa} \cdot \mathrm{s}(3.5 \mathrm{cP})$ at $27^{\circ} \mathrm{C}$ to $0.0028 \mathrm{~Pa} \mathrm{~s}(2.8 \mathrm{cP})$ at $45^{\circ} \mathrm{C}$, and $0.0023 \mathrm{~Pa} \mathrm{~s}(2.3 \mathrm{cP})$ at $65^{\circ} \mathrm{C}$. Barker and Hedengren (2003) report representative temperatures of the liquid and settled solids layers as $38^{\circ}$ and $72^{\circ} \mathrm{C}$, respectively. The samples with the temperature most representative of the mixed waste are therefore those at $45^{\circ} \mathrm{C}$, indicating a liquid viscosity of $0.0028 \mathrm{~Pa} \mathrm{~s}(2.8 \mathrm{cP})$.

The liquid viscosity values are in reasonable agreement with those reported in Jewett et al. (2002) for HLW feed tank C-104. Figure 2.1 shows the trend in the liquid viscosity with liquid density for this tank as well as data obtained by ball rheometer deployment (Stewart et al. 1996), core sample analysis, and dilution studies in saltcake tanks AN-104 (Herting 1998), AW-101 (Herting 1999), and SY-101 ${ }^{\text {(a) }}$ (Reynolds 1992). The AY-102 liquid viscosity is in general agreement with this trend.

(a) Person JC. April 22, 1999. Dilution Studies of Tank 241-SY-101 Waste. Preliminary Results. Internal Memo 82100-99-015 to NW Kirch, Numatec Hanford Corporation, Richland, WA. 


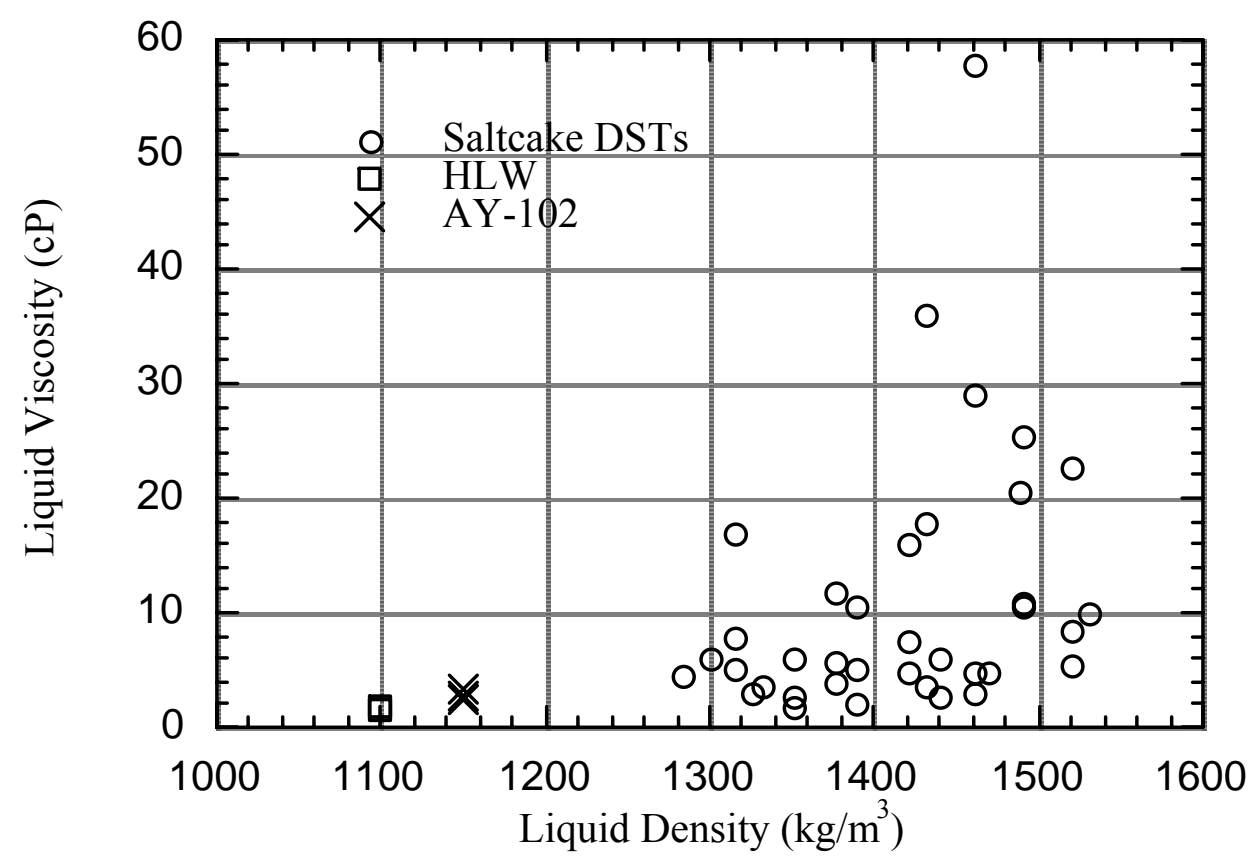

Figure 2.1. Hanford Liquid Viscosity as a Function of Liquid Density

\subsection{AY-102 Solid Waste Properties}

In this section, waste parameters relating to the settled solids layer are elucidated. These parameters include the settled solids layer depth, the settled solids and undissolved solid densities, the solid volume fraction in the settled solids, the solid particle size distribution, the slurry viscosity, and the yield stress in shear (shear strength) of the settled solids layer.

\subsubsection{Settled Solids Layer Depth, Density, and Solid Volume Fraction}

The settled solids layer in AY-102 is approximately 62 in. $(1.58 \mathrm{~m})$ thick (Barker and Hedengren 2003 ) with a bulk density of $1,570 \mathrm{~kg} / \mathrm{m}^{3}$ (TWINS). The solids in this layer comprise mainly $\mathrm{Al}(\mathrm{OH})_{3}$, $\mathrm{Fe} 0(\mathrm{OH}), \mathrm{Mn}(\mathrm{OH})_{2}$, and $\mathrm{NaAlCO}_{3}(\mathrm{OH})_{2}$ (Jewett et al. 2002). The solid volume fraction $\left(\mathrm{C}_{\mathrm{V}}\right)$ of this layer may be determined from the total mass being a summation of the liquid and solid mass, or

$$
\mathrm{C}_{\mathrm{V}}=\frac{\rho_{\mathrm{B}}-\rho_{\mathrm{L}}}{\rho_{\mathrm{S}}-\rho_{\mathrm{L}}}
$$

where $\rho_{\mathrm{B}}, \rho_{\mathrm{S}}$, and $\rho_{\mathrm{L}}$ denote the bulk (settled solids), undissolved solids, and liquid densities, respectively. The interstitial liquid is assumed to be synonymous with the supernatant liquid. The undissolved solids density can be estimated by the various techniques discussed below.

The undissolved solids crystal density is approximately 2,900 to $3,400 \mathrm{~kg} / \mathrm{m}^{3}$, as determined from the waste chemistry data in TWINS, Jewett et al. (2002), and preliminary Environmental Simulation Program 
(ESP) results. ${ }^{\text {(a) }}$ However, these estimates do not account for agglomerations, flocculation, and the like and may therefore be considered an upper bound. Measurements of the water mass fraction in the liquid $\left(\mathrm{w}_{\mathrm{L}}\right)$ and bulk settled solids $\left(\mathrm{w}_{\mathrm{B}}\right)$ may also be used to determine the undissolved solids density using Eq. (2.3) (Onishi et al. 2002):

$$
\rho_{\mathrm{S}}=\frac{\rho_{\mathrm{B}}\left(1-\frac{\mathrm{w}_{\mathrm{B}}}{\mathrm{w}_{\mathrm{L}}}\right)}{1-\frac{\rho_{\mathrm{B}}}{\rho_{\mathrm{L}}}\left(\frac{\mathrm{w}_{\mathrm{B}}}{\mathrm{w}_{\mathrm{L}}}\right)}
$$

As presented in Onishi et al. (2002), this methodology is extremely sensitive to the measured water content and often produces erroneous results. Applied to AY-102 data from TWINS, this methodology results in an undissolved solids density of approximately $2,200 \mathrm{~kg} / \mathrm{m}^{3}$, which is lower than that determined from the solids' crystal densities. The reported water content in the AY-102 liquid is approximately $10 \%$ greater than that indicated by an empirical relation encompassing liquid density and mass fraction data from 77 Hanford Tanks (TWINS). With the extrapolated liquid water content, the solids density estimate increases to approximately $2,400 \mathrm{~kg} / \mathrm{m}^{3}$.

To reconcile these undissolved solids density estimates and in lieu of AY-102 data, we considered waste data from HLW Tank AZ-101. The mass fraction of undissolved solids $\left(\mathrm{w}_{\mathrm{S}}\right)$ in AZ-101 waste samples (Urie et al. 2002) may be expressed as a function of the bulk, liquid, and undissolved solid densities of the samples by

$$
\mathrm{w}_{\mathrm{S}}=\frac{\rho_{\mathrm{B}}-\rho_{\mathrm{L}}}{\rho_{\mathrm{S}}-\rho_{\mathrm{L}}}\left(\frac{\rho_{\mathrm{S}}}{\rho_{\mathrm{B}}}\right)
$$

Using Eq. (2.4) to fit the data of Urie et al. (2002), we determined that the best fit (from a least squares regression) to the reported mass fraction of undissolved solids in AZ-101 was achieved with an undissolved solids density of approximately $85 \%$ of that determined from analyzing the solids'crystal density. This apparent density reduction is not unexpected with agglomerations in the solids. In AY-102, this reduction corresponds to approximately 2,500 to $2,900 \mathrm{~kg} / \mathrm{m}^{3}$. In consideration of the results from Eq. (2.3), 2,500 kg/m $\mathrm{m}^{3}$ is used for the undissolved solids density in AY-102. Applying the settled solids density $\left(1,570 \mathrm{~kg} / \mathrm{m}^{3}\right)$, liquid density $\left(1,150 \mathrm{~kg} / \mathrm{m}^{3}\right)$, and undissolved solids density $\left(2,500 \mathrm{~kg} / \mathrm{m}^{3}\right)$ to Eq. (2.2), the solid volume fraction in the settled solids of AY-102 is 0.31 .

\subsubsection{Settled Solids Layer Particle Size}

A light-scattering particle size distribution (PSD) analysis was conducted on AY-102 samples (Bechtold et al. 2002). Two PSD measurements were conducted on the core sample composite. Altering the instrumentation setup or ultrasonic treatment (to investigate possible flocculation and deagglomeration) had only minimal effect on the particle sizes. Approximately half of the solids were observed to have diameters less than $2.5 \mu \mathrm{m}$. The volume-based particle size distribution for AY-102 is

(a) Personal communication with LA Mahoney, June 2002. 
listed in Table 2.1. The particle size indicates the upper bound for the given volume fraction (i.e., $50 \%$ of the particles by volume are smaller than $2.5 \mu \mathrm{m}, 25 \%$ are between 2.5 and $5.7 \mu \mathrm{m}$, etc.).

Table 2.1. Volume Particle Size Distribution for AY-102 (from Bechtold et al. 2002)

\begin{tabular}{||c|c||}
\hline Particle Size $(\boldsymbol{\mu m})$ & Volume Fraction \\
\hline 2.5 & 0.50 \\
\hline 5.7 & 0.25 \\
\hline 12 & 0.20 \\
\hline 16.8 & 0.05 \\
\hline
\end{tabular}

\subsubsection{Slurry Viscosity}

The rheological behavior of the slurry in AY-102 was developed from the data of Warrant (2001). From the available data, the viscosity of the slurry is essentially independent of the strain rate. The slurry viscosity model used in this analysis therefore describes the viscosity solely as a function of the solids volume fraction.

Viscosity measurements on AY-102 slurry were conducted at $27^{\circ}, 45^{\circ}$, and $65^{\circ} \mathrm{C}$. The samples at $45^{\circ} \mathrm{C}$ are the most representative of the mixed waste (liquid at $38^{\circ} \mathrm{C}$ and settled solids at $72^{\circ} \mathrm{C}$ ) (Barker and Hedengren 2003). The shear stress as a function of strain data for samples at 0.04, 0.06, 0.08, and 0.12 undissolved solids by volume was fit by Eq. (2.1), and typically $\mathrm{R}^{2}$ values greater than 0.95 were achieved. The data are summarized in Table 2.2. An expression relating the slurry viscosity to the solids volume fraction in the slurry of the form

$$
\mu_{\mathrm{SL}}=\mu \cdot \mathrm{a}^{\frac{\mathrm{C}_{\mathrm{V}}}{\mathrm{C}_{\mathrm{V} \text { max }}}}
$$

was used to model the slurry viscosity (Onishi and Trent 1999). In Eq. (2.5), $\mu_{\mathrm{SL}}$ is the slurry viscosity, $\mu$ is the liquid viscosity, and $\mathrm{C}_{\mathrm{Vmax}}$ is the maximum slurry solids volume fraction $(0.32$ was used in this analysis). The constant "a" was determined using a least squares regression analysis, comparing Eq. (2.5) to the data listed in Table 2.2. The liquid viscosity is 0.0028 Pa-s (see Section 2.1). The fit with $\mathrm{a}=2.6238$ is shown in Figure 2.2.

Table 2.2. Slurry Viscosity for AY -102

\begin{tabular}{||c|c||}
\hline Solid Volume Fraction & Slurry Viscosity (Pa s) [cP] \\
\hline 0.04 & $0.0028[2.8]$ \\
\hline 0.06 & $0.003[3.0]$ \\
\hline 0.08 & $0.0035[3.5]$ \\
\hline 0.12 & $0.0043[4.3]$ \\
\hline
\end{tabular}




\section{- Data $\square$ Fit}

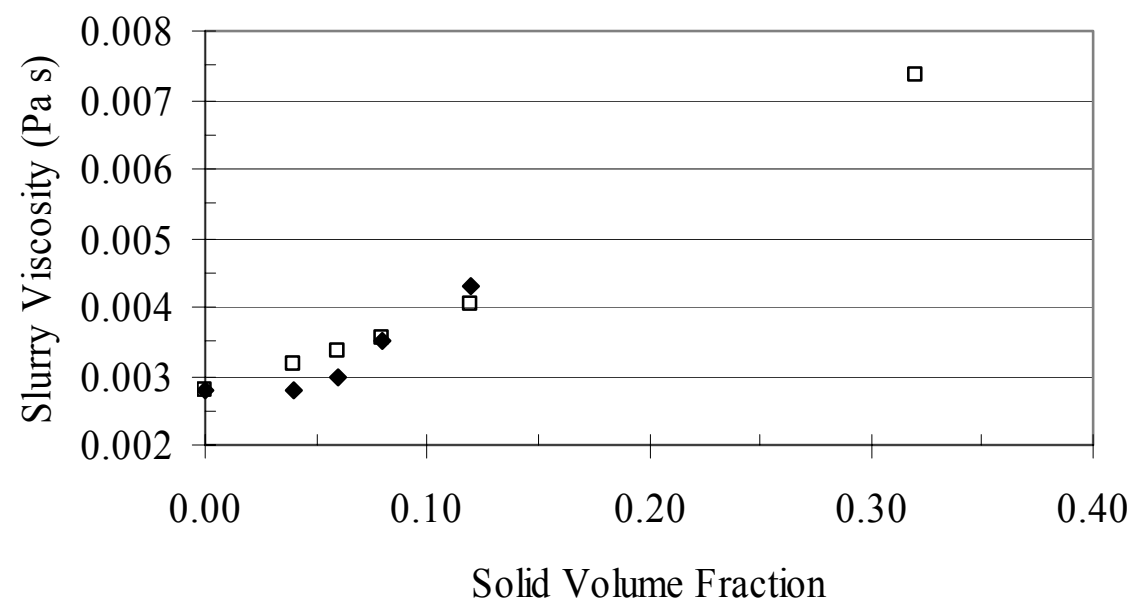

Figure 2.2. AY-102 Slurry Viscosity as a Function of the Solids Volume Fraction

\subsubsection{Settled Solids Layer Shear Strength}

There are no in situ shear strength measurements available for AY-102. The shear strength of the AY-102 settled solids is therefore estimated based on ex-tank measurements as determined from waste core extrusions. Ex situ tank shear strength data from a rotating shear vane are also considered.

\subsubsection{Core Extrusion Shear Strength Estimates}

A core extrusion shear strength estimation technique for settled solids that provides results similar to in situ measurements was presented in the appendix of Rassat et al. (2003). This technique is based on extrusion length and was developed from the results presented in Gauglitz and Aikin (1997). A brief summary of the extrusion length methodology is presented below.

Gauglitz and Aikin (1997) horizontally extruded simulants of known shear strength and reported the length at which the extrusion exhibited "failure." With these data, we have the ability to correlate the shear strength of the material directly with the functional form of maximum tensile stress in a round cantilever beam:

$$
\tau_{\mathrm{y}}=\mathrm{K} \frac{\rho g \mathrm{~L}^{2}}{\mathrm{~d}}
$$

where $\mathrm{L}$ is the beam failure length, $\mathrm{d}$ is the beam diameter [core extrusion diameter: $1.125 \mathrm{in} .(0.029 \mathrm{~m})$ ], $\rho$ is the material density (AY-102 settled solids density, $1,570 \mathrm{~kg} / \mathrm{m}^{3}$ ), $\mathrm{g}$ is the acceleration of gravity, and $\mathrm{K}$ is a proportionality coefficient. The proportionality coefficient $\mathrm{K}$ of Eq. (2.6) provides a means to compute the shear strength of a material given its density and the plastic failure length of a horizontal extrusion, and is likely a function of the material microstructure. 
The simulants used by Gauglitz and Aikin (1997) were chosen to reflect the variety of mechanical behavior typical of wastes from the Hanford tanks. A proportionality coefficient was determined from the data for each simulant. If we assume that the simulants bound the mechanical behavior of Hanford waste, we can expect that the shear strength of the waste will be between 0.89 and 1.45 times $\rho g L^{2} / \mathrm{d}$. These proportionality coefficients are referred to as the lower and upper bound extrusion length estimates, respectively. The best fit with Eq. (2.6) applied to the entire group of simulants is obtained with a K of 1.15 and is termed the best estimate.

Results with this methodology (extrusion length) are similar in magnitude and reproduce the same trends as other in situ shear strength measurements for select saltcake DSTs. It was concluded in Rassat et al. (2003) that in the absence of definitive in situ measurements, or in support of them, the extrusion length methodology is expected to produce representative results for shear strength.

The extrusion length methodology was used to investigate horizontal core extrusion videos (for waste cores 270-273, 289, 290, and 300) from AY-102. The earliest core in relation to the C-106/AY-102 sluicing activities (sluicing operations were completed in October 1999) was core 270, initiated on December 10, 1999. Measurable (i.e., the length and diameter could be measured) initial extrusion failure lengths were identified for 22 of the possible 32 applicable (i.e., from the sludge layer) core segments. In some instances, multiple measurements were available from a single waste core segment.

Extrusion lengths ranging from 0.98 to 2.14 in. were observed. Example extrusions from the AY-102 cores are shown in the following figures. In Figure 2.3, the second measurement from core 270, segment 12 is shown. The extrusion failure length is $1.8 \mathrm{in}$., resulting in a best-estimate shear strength of 1,300 Pa. The measurement from core 290, segment 12A is shown in Figure 2.4. A best-estimate shear strength of $1,790 \mathrm{~Pa}$ was determined from the extrusion failure length of $2.12 \mathrm{in.}$

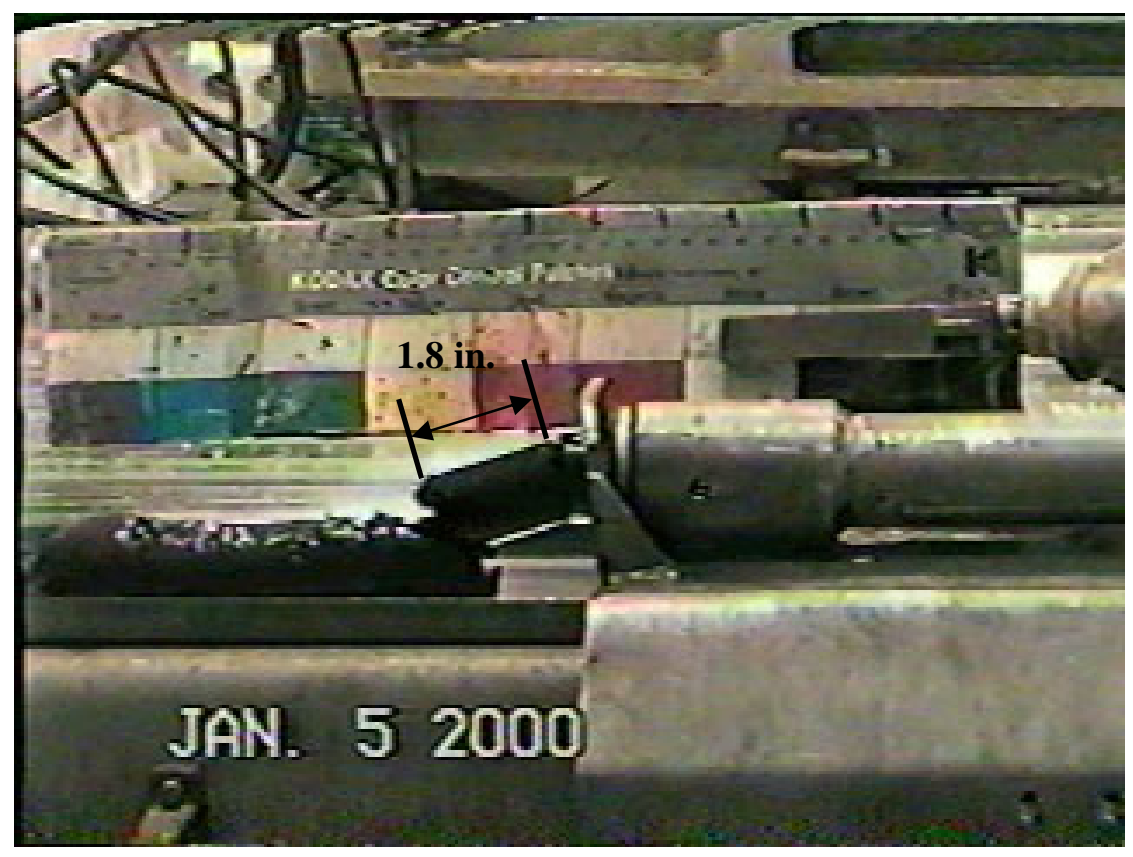

Figure 2.3. AY-102 Horizontal Core Extrusion Failure Length (Core 270, Segment 12, Measurement 2) 


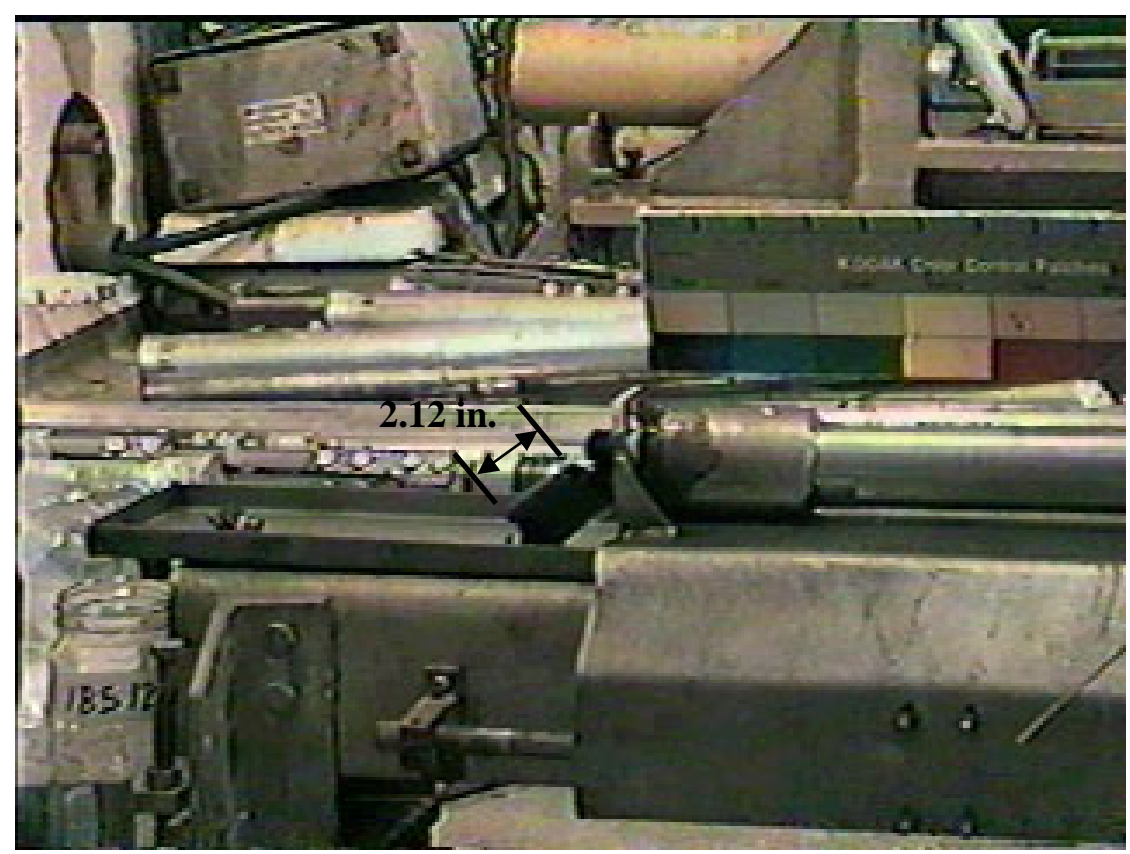

Figure 2.4. AY-102 Horizontal Core Extrusion Failure Length (Core 290, Segment 12A)

The extrusion length methodology results for AY-102 are presented in Table 2.3 and Figure 2.5. The 95\% confidence interval range over all the results (upper and lower bounds and best estimates) is 390 to 2,230 $\mathrm{Pa}$, with a median value of $1,090 \mathrm{~Pa}$.

These extrusion length shear strength results, based on the analysis in Rassat et al. (2003), are expected to be representative of in situ conditions. However, the limitations of the methodology (uncertainties in the methodology itself as well as in the extrusion length measurements) and the applicability of the results to the entire settled solids layer, must be considered. Although numerous extrusion length estimates are available (Table 2.3), the available core samples (waste cores 270-273, 289, 290, and 300) from which these results were determined were all taken in three individual risers $34.75 \mathrm{ft}$ from the tank center ( $2.75 \mathrm{ft}$ from the wall). Horizontal homogeneity in the settled solids may be expected due to the tank history; the applicability of the results to the entire settled solids layer, however, is unknown.

\subsubsection{Shear Vane Shear Strength Measurements}

The shear strength of the AY-102 settled solids has been evaluated using a rotating shear vane. ${ }^{\text {(a) }}$ Sample history (e.g., agitation, temperature changes, mixing) may have a significant effect on the results. Although the results of shear vane measurements may be significantly larger than in situ measurements in saltcake tanks (Gauglitz and Aikin 1997; Heath 1987), ${ }^{(\mathrm{b})}$ more favorable comparisons may be made in sludge tanks (AY-102 is classified as a sludge tank) (Barker and Lechelt 2000). ${ }^{(\mathrm{c})}$

(a) Bechtold DB. March 28, 2001. "Correction of Shear Strength Measurements Reported by 222-S Laboratory." Memorandum 8D500-DBB-01-018 to KE Bell, RA Esch, and FH Steen, Fluor Hanford Inc., Richland, WA.

(b) Bredt PR, JD Hudson, and JM Tingey. 1995. Effects of Dilution on the Physical, Rheological, and Chemical Properties of Tank 241-SY-103. Letter report MIT 092995, Pacific Northwest National Laboratory, Richland, WA.

(c) Wells BE and SA Barker. 2003. Summary of Yield Stress in Shear Data for Hanford Waste. Letter Report TWS03.044, Pacific Northwest National Laboratory, Richland, WA. 
Table 2.3. AY-102 Extrusion Length Shear Strength Results

\begin{tabular}{||c|c|c|c|c||}
\hline \multirow{2}{*}{ Core } & \multirow{2}{*}{ Segment } & \multicolumn{3}{|c|}{ Shear Strength (Pa) } \\
\cline { 3 - 5 } & & Upper Bound & Best Estimate & Lower Bound \\
\hline 270 & 11 & 1840 & 1460 & 1130 \\
\hline 270 & 12 & 1300 & 1030 & 800 \\
\hline 270 & 12 & 1630 & 1300 & 1000 \\
\hline 270 & 12 & 2220 & 1760 & 1360 \\
\hline 271 & 9 & 1810 & 1440 & 1110 \\
\hline 271 & 11 & 2300 & 1830 & 1410 \\
\hline 272 & 9 & 1950 & 1550 & 1200 \\
\hline 272 & 11 & 1950 & 1550 & 1200 \\
\hline 272 & 11 & 1690 & 1340 & 1030 \\
\hline 272 & 12 & 790 & 620 & 480 \\
\hline 273 & 10 & 1080 & 860 & 660 \\
\hline 273 & 12 & 1000 & 790 & 610 \\
\hline 273 & 12 & 1210 & 960 & 740 \\
\hline 273 & 12 & 1690 & 1340 & 1030 \\
\hline 289 & 12 & 1730 & 1370 & 1060 \\
\hline 289 & 12 & 1950 & 1550 & 1200 \\
\hline 289 & 13 & 950 & 760 & 590 \\
\hline 290 & 10 & 870 & 690 & 530 \\
\hline 290 & 11 & 1280 & 1020 & 790 \\
\hline 290 & $12 \mathrm{~A}$ & 2260 & 1790 & 1390 \\
\hline 290 & $12 \mathrm{RA}$ & 1070 & 850 & 660 \\
\hline 300 & 11 & 1770 & 1410 & 1090 \\
\hline 300 & 11 & 850 & 670 & 520 \\
\hline 300 & 11 & 600 & 480 & 370 \\
\hline 300 & 11 & 490 & 390 & \\
\hline
\end{tabular}

The shear vane results for settled solids in AY-102 are given in Table 2.4. All samples were from cores 270-273 (same as 14 extrusion length estimates; see Table 2.3 ). The 95\% confidence interval range is $65 \mathrm{~Pa}$ to $6,860 \mathrm{~Pa}$, with a median value of $510 \mathrm{~Pa}$. 


\section{$\diamond$ Upper Bound - Best Estimate $\Delta$ Lower Bound}

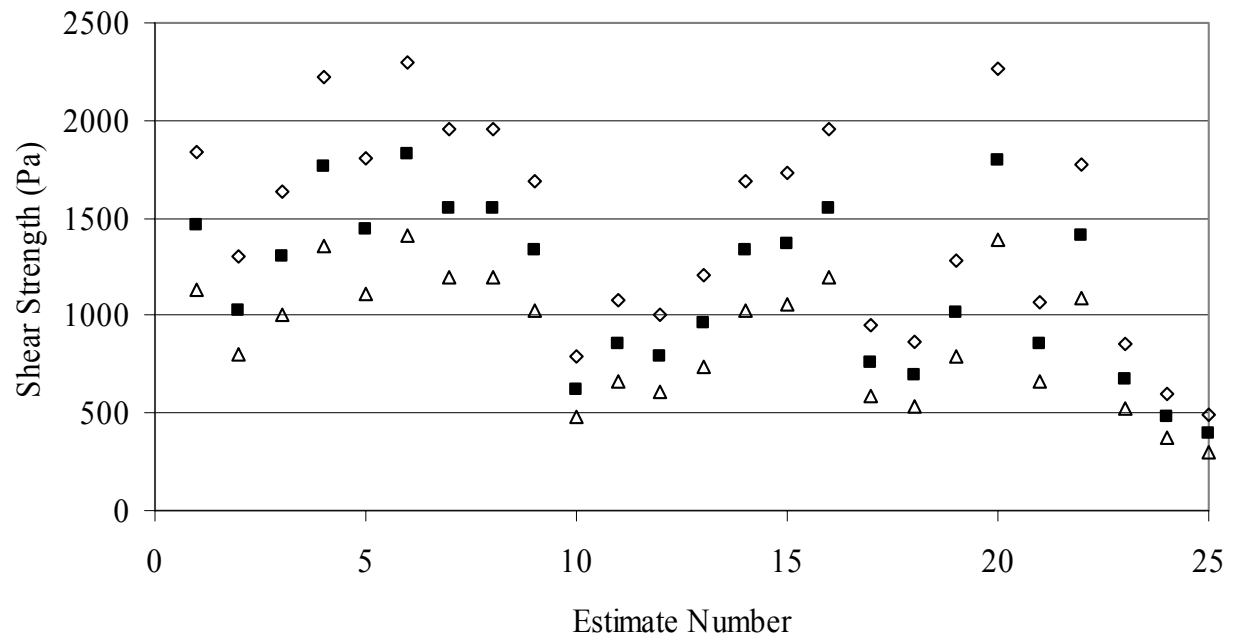

Figure 2.5. Shear Strength of AY-102 Settled Solids Layer Estimated from Waste Core Extrusions

Table 2.4. AY-102 Shear Vane Shear Strength Results ${ }^{(a)}$

\begin{tabular}{|c|c|c|}
\hline Core & Segment & Shear Strength (Pa) \\
\hline 270 & 10 & 177 \\
\hline 270 & 10 & 6189 \\
\hline 270 & 11 & 70 \\
\hline 270 & 11 & 3318 \\
\hline 270 & 12 & 839 \\
\hline 270 & 12 & 890 \\
\hline 271 & 9 & 953 \\
\hline 271 & 10 & 414 \\
\hline 271 & 10 & 940 \\
\hline 271 & 11 & 164 \\
\hline 271 & 11 & 392 \\
\hline 271 & 12 & 479 \\
\hline 271 & 12 & 720 \\
\hline 272 & 9 & 1104 \\
\hline 272 & 10 & 378 \\
\hline 272 & 10 & 435 \\
\hline 272 & 11 & 470 \\
\hline 272 & 11 & 751 \\
\hline 272 & 12 & 533 \\
\hline 272 & 12 & 835 \\
\hline 273 & 9 & 1251 \\
\hline 273 & 10 & 250 \\
\hline 273 & 10 & 507 \\
\hline 273 & 11 & 57 \\
\hline 273 & 11 & 93 \\
\hline 273 & 12 & 474 \\
\hline 273 & 12 & 8096 \\
\hline \multicolumn{3}{|c|}{$\begin{array}{l}\text { (a) DB Bechtold to KE Bell, RA Esch, and FH Steen. March 28, } 2001 . \\
\text { "Correction of Shear Strength Measurements Reported by 222-S Laboratory } \\
\text { Memorandum 8D500-DBB-01-018, Fluor Hanford Inc., Richland, WA. }\end{array}$} \\
\hline
\end{tabular}




\subsubsection{Shear Strength Summary}

Distributions of the extrusion length and shear vane shear strength results are compared in Figure 2.6. Although some higher results are achieved with the shear vane, these high results have a low probability of occurrence ( 0.037 or 1 out of 27 measurements) and are outliers. There is significantly more scatter in the shear vane results. ${ }^{\text {(a) }}$ The median of the shear vane results is lower than the extrusion length results (510 $\mathrm{Pa}$ and 1,090 $\mathrm{Pa}$, respectively) due to the high probability of results less than $600 \mathrm{~Pa}$.

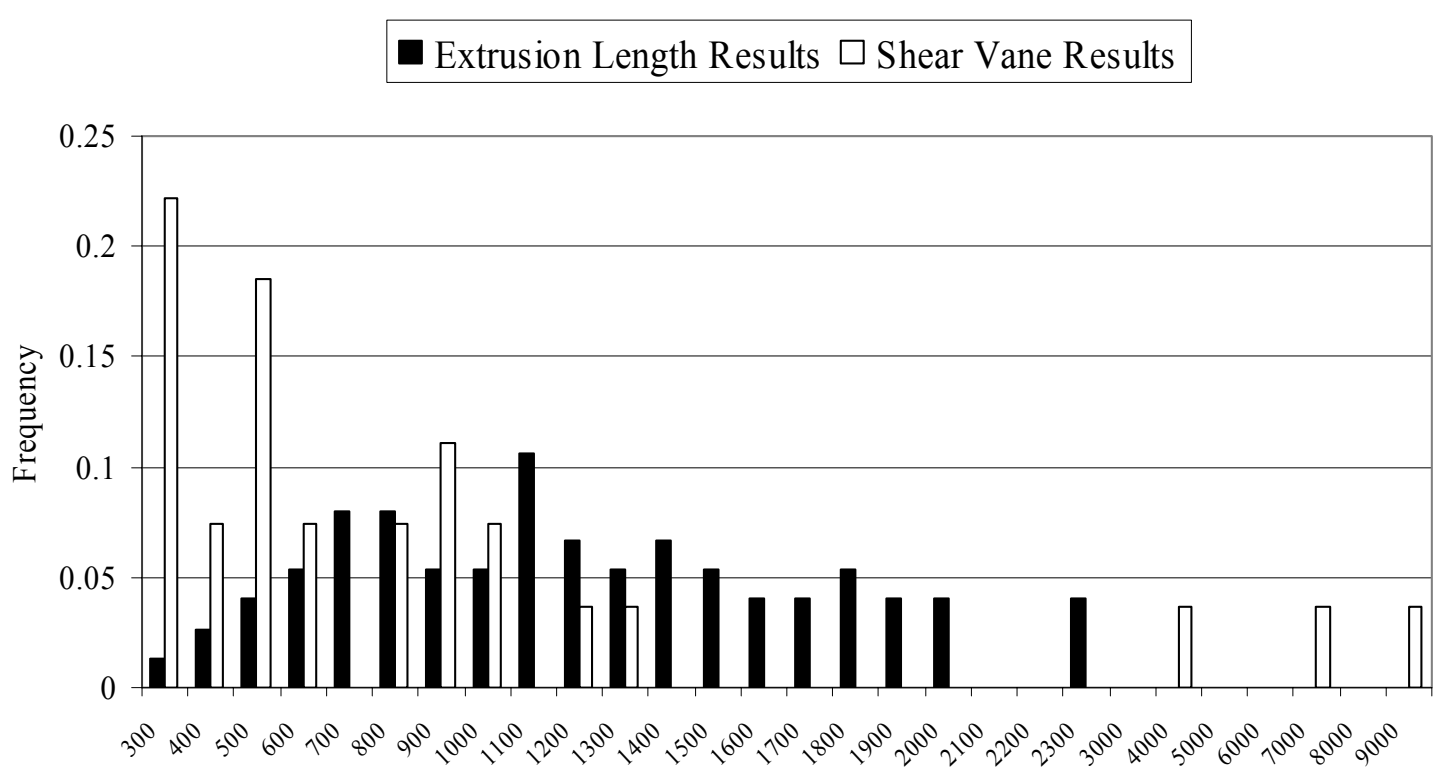

Shear Strength $(\mathrm{Pa})$

Figure 2.6. Shear Strength of AY-102 Settled Solids Layer: Extrusion Length and Shear Vane Results

Core segments 270-11, 270-12, 271-9, 271-11, 272-9, 272-11, 272-12, 273-10, and 273-12 have both extrusion length and shear vane estimates for the shear strength. No correlation of extrusion length and shear vane results is identifiable between core segments (see Figure 2.7). In Figure 2.7, the points are the median values, and the "error bars" represent the range of the measurements from Tables 2.3 and 2.4. As such, they do not represent the uncertainties in the measurements (i.e., uncertainty of the techniques and applicability to the entire core segment at in situ conditions); they represent the variability in the specific measurements. The shear vane results typically had two measurements per core segment; results with no error bars denote a single measurement. It is again apparent that the variability in measurement for a given segment and/or core is greater with the shear vane. The extrusion length results are generally larger than those of the shear vane with the notable exception of core 273, segment 12.

The extrusion length shear strength results for AY-102 are comparable to other similar Hanford wastes. Shear strength data (measurements are typically average or median values) from the various ex situ (Couette type viscometer, shear vane, extrusion length, etc.) and in situ tank measurements (ball

(a) Comparing the standard deviations, $490 \mathrm{~Pa}$ for the extrusion length estimates and 1,860 Pa for the shear vane, illustrates the larger scatter of the shear vane results. 
$\diamond$ Extrusion Length $\square$ Shear Vane

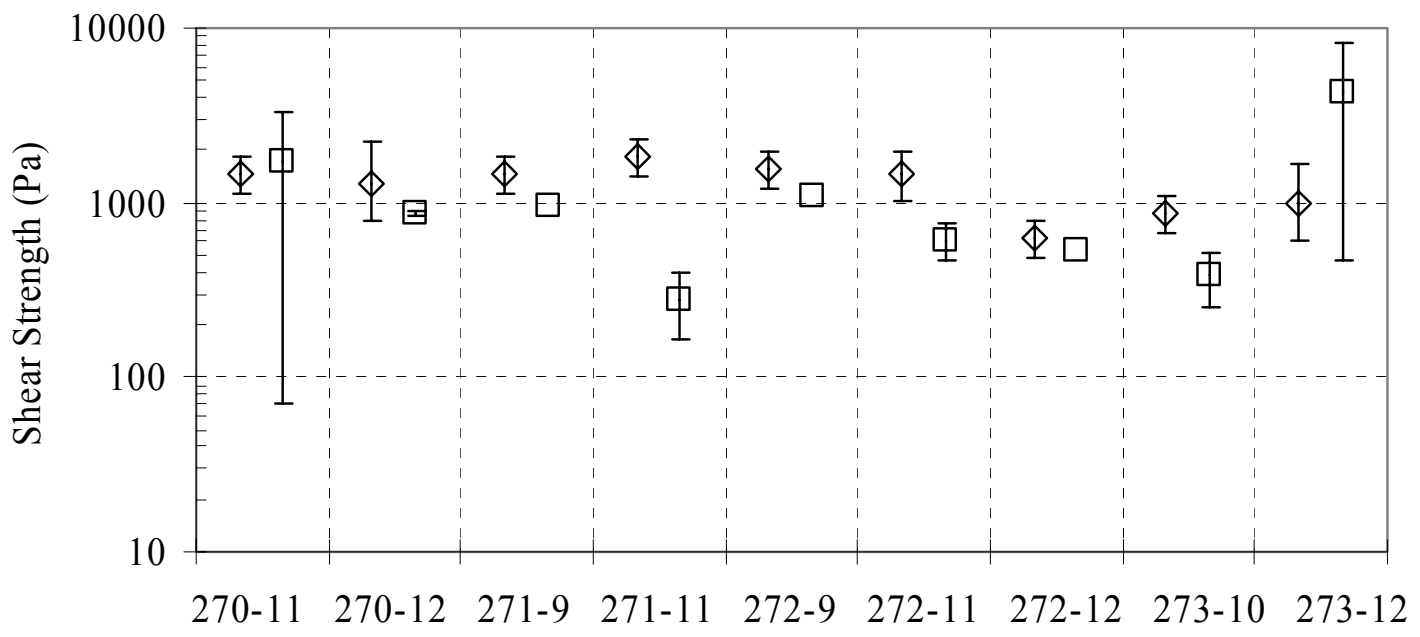

\section{Core Segment}

Figure 2.7. Shear Strength of AY-102 Settled Solids Layer: Extrusion Length and Shear Vane Results from Specific Core Segments ${ }^{(a)}$

rheometer) taken on Hanford waste have been compared. ${ }^{(b)}$ Representative shear strength distributions based on waste type (sludge or saltcake with less than or more than $1 \mathrm{~m}$ of overlaying liquid) were postulated. Note that these distributions are representative values and should not be substituted for specific analysis of a given waste. They do, however, illustrate similarities and thus provide a rough check of the results listed above. For AY-102's waste type (sludge with greater than $1 \mathrm{~m}$ of overlying liquid), two other Hanford waste tanks had reported shear strength values; AW-103 and AZ-102. The extrusion length methodology has also been applied to AZ-101. The representative shear strength distribution for the average or median shear strength values for these waste tanks (as determined by goodness-of-fit tests in Crystal $\mathrm{Ball}^{\mathrm{TM}}$ ) ranged from approximately $370 \mathrm{~Pa}$ to $1,750 \mathrm{~Pa}$, compared with $1,090 \mathrm{~Pa}$ and $510 \mathrm{~Pa}$ obtained by AY-102 core extrusion and the shear vane measurements, respectively. In comparison, saltcake wastes with greater than $1 \mathrm{~m}$ of liquid ranged from approximately 100 to $190 \mathrm{~Pa}$, saltcake waste with less than $1 \mathrm{~m}$ of liquid from approximately 240 to $1,410 \mathrm{~Pa}$, and sludge with less than $1 \mathrm{~m}$ of liquid ranged from approximately 550 to $2,250 \mathrm{~Pa}$.

The extrusion length shear strength results (median and 95\% confidence interval) were chosen to be used in the current analysis. They have less variability than the shear vane results, may be more representative of in situ conditions (this is uncertain), include data for more waste samples, and are in general agreement with similar waste types. With a median value more than twice that of the shear vane, they are also more conservative for mobilization analyses (i.e. more limiting).

(a) Memorandum from DB Bechtold to KE Bell, RA Esch, and FH Steen. March 28, 2001. "Correction of Shear Strength Measurements Reported by 222-S Laboratory." 8D500-DBB-01-018, Fluor Hanford Inc., Richland, WA.

(b) Wells BE and SA Barker. 2003. Summary of Yield Stress in Shear Data for Hanford Waste. Letter Report TWS03.044, Pacific Northwest National Laboratory, Richland, WA. 


\subsection{AY-102 Waste Properties Summary}

The AY-102 waste properties presented in Sections 2.1 and 2. 2 for the liquid, settled solids, and undissolved solids are summarized in Table 2.5. Data sources are presented and referenced in the preceding sections. Parameter values are typically median values.

Table 2.5. AY-102 Waste Properties Summary

\begin{tabular}{|l|l|l|}
\hline \multirow{4}{*}{ Liquid } & \multicolumn{1}{|c|}{ Parameter } & \multicolumn{1}{c|}{ Value (units) } \\
\cline { 2 - 3 } & Depth & $186(\mathrm{in})$ \\
\cline { 2 - 3 } & Density & $1,150\left(\mathrm{~kg} / \mathrm{m}^{3}\right)$ \\
\cline { 2 - 3 } & Viscosity & $2.8(\mathrm{cP})$ \\
\hline \multirow{5}{*}{ Uettled Solids } & Depth & $62(\mathrm{in})$ \\
\cline { 2 - 3 } & Density & $1,570\left(\mathrm{~kg} / \mathrm{m}^{3}\right)$ \\
\cline { 2 - 3 } & Solid volume fraction & 0.31 \\
\cline { 2 - 3 } & Viscosity & $0.0028 \sim 0.0071(\mathrm{~Pa}-\mathrm{s})$ \\
\cline { 2 - 3 } & Shear strength & $1,090(\mathrm{~Pa}) ;$ median value \\
& & $2,230(\mathrm{~Pa}): 97.5$ percentile \\
\hline & Density & $2,500\left(\mathrm{~kg} / \mathrm{m}^{3}\right)$ \\
\cline { 2 - 3 } & Particle size distribution & $2.5 \sim 16.8(\mu \mathrm{m})$ \\
\hline
\end{tabular}




\subsection{Pump Jet Mixing Simulation Results}

\subsection{Simulation Conditions}

The objective of this study was to determine whether two 300-hp mixer pumps would mobilize Tank AY-102 sludge waste and mix it with the overlaying supernatant liquid well enough to be able to retrieve the resulting slurry from the tank. If two mixer pumps are not sufficient to mobilize the waste, four mixer pumps would be an option. Tank AY-102 has a diameter of $75 \mathrm{ft}(23 \mathrm{~m})$ and an operating depth of $35 \mathrm{ft}$ $(11 \mathrm{~m})$. It contains $248 \mathrm{in} .(6.3 \mathrm{~m})$ of HLW that comprises 62 in. $(1.58 \mathrm{~m})$ of sludge and 186 in. $(4.72 \mathrm{~m})$ of supernatant liquid, as discussed in Section 2.

Two 300-hp centrifugal submersible pumps are expected to be used for mobilizing and mixing the waste, as shown in Figure 3.1. The pumps have a 32-in.- (0.81-m-) diameter inlet at the bottom and two 6-in.- $(0.15-\mathrm{m}$-) diameter injection nozzles whose center is 9 in. $(0.23 \mathrm{~m})$ above the bottom of the pump. These pumps would be placed 6 in. $(0.15 \mathrm{~m})$ above the tank bottom; thus the centerline of the waste injection nozzles would be 15 in. $(0.38 \mathrm{~m})$ from the tank bottom. Two pumps would be installed $22 \mathrm{ft}$ $(6.7 \mathrm{~m})$ from the tank center, diagonally opposite each other, as shown in Figure 3.2. Submersible motors would operate these pumps at a rate such that pumps would inject AY-102 waste through two injection nozzles at an exit velocity of $60 \mathrm{ft} / \mathrm{sec}(18.3 \mathrm{~m} / \mathrm{s}$ ). The pumps (thus the injection nozzles) would be oscillated $180^{\circ}$ at $0.2 \mathrm{rpm}$. The AY-102 waste would be multicomponent and multiphase, consisting of solids and liquid. Table 2.5 summarizes the waste properties and conditions used for AY-102 pump jet mixing simulations.

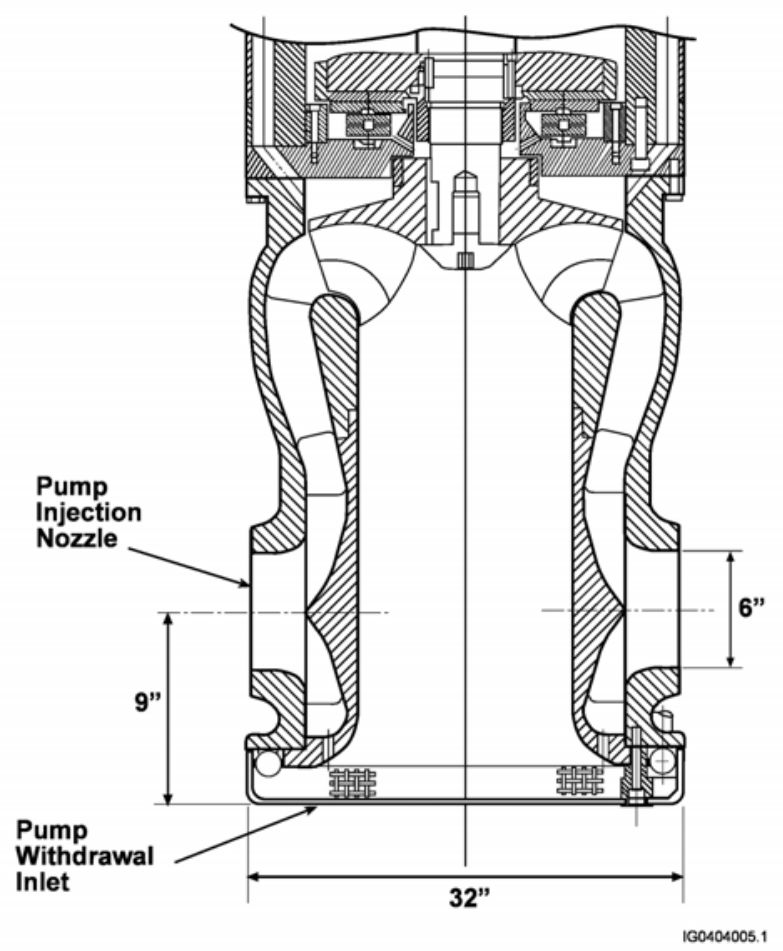

Figure 3.1. AY-102 Mixer Pump 


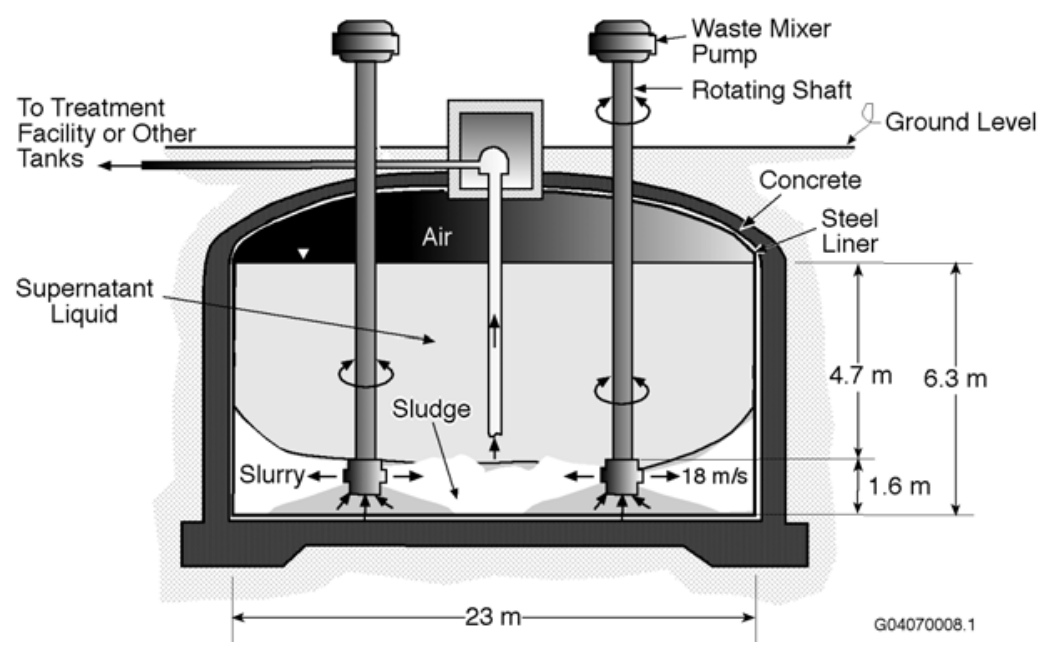

Figure 3.2. Tank AY-102 with Two Off-Center Mixer Pumps

As discussed in Section 2, the most uncertain parameter is the shear strength (yield strength, yield stress). A force greater than the shear strength would mobilize the sludge. Figure 2.6 presents estimated shear strength values based on estimates from the sludge core extrusion length and shear vane measurements. The median value of the shear strength based on the core extrusion length is 1,090 Pa. The 97.5 percentile of the AY-102 shear strength value is 2,230 Pa. A review of Hanford tank wastes indicated that the average or median shear strength of sludge waste with more than $1 \mathrm{~m}$ of supernatant liquid ranges from about $370 \mathrm{~Pa}$ to $1,750 \mathrm{~Pa}$, so the 97.5 percentile estimate is similar to the upper limit of these values. On the other hand, the median of the shear vane results is $510 \mathrm{~Pa}$, though there are some higher measured values. Because most shear strength estimates obtained by core extrusion observations are more conservative (greater shear strength values) than those from shear vane measurements, we used shear strength estimated with the former method.

To adequately cover the uncertainty of the AY-102 shear strength values, we evaluated the pump jet mixing performance for shear strength of both 1,090 $\mathrm{Pa}$ (median) and 2,230 $\mathrm{Pa}$ (97.5 percentile). We assigned that the shear strength, F, would be reduced as a function of the solids volume fraction and shear rate, according to Ellwood et al. (1990):

$$
\begin{gathered}
F_{i}=\tau_{0}\left(1-e^{-n C_{V}}\right) \frac{\left(1-e^{-m \Pi}\right)}{\Pi} \gamma_{i, j=1,2,3} \\
\gamma_{i, j}=\left(\frac{\partial U_{i}}{\partial x_{j}}+\frac{\partial U_{j}}{\partial x_{i}}\right)
\end{gathered}
$$

where $m$ is strain rate exponential shape factor, $n=$ moisture content exponential shape factor, $U_{i}$ and $U_{j}$ are velocities in $i$ and $j$ directions, $x_{i}$, and $x_{j}$ are coordinates of $i$ and $j$ directions, $\tau_{0}$ is the original shear strength of the sludge, when the sludge is not moving, $\Pi$ is the second invariant of the strain rate tensor, and $\gamma_{i, j}$ is the rate of strain. 
We used the three-dimensional TEMPEST code (Onishi and Trent 1999) to determine whether two rotating 300-hp mixer pumps would adequately mix the AY-102 waste (see Figure 3.2). As discussed in Section 2.2.2, we divided the AY-102 solids into four particle size fractions represented by 2.5, 5.7, 12, and $16.8 \mu \mathrm{m}$, as shown in Table 2.1. The smallest size fraction (Solid 1) makes up half (volume based) of the total solids in the sludge layer. The solids occupy $31 \mathrm{vol} \%$ of the settled solids (sludge) layer.

We assumed that the mixer pumps oscillate at $0.2 \mathrm{rpm}$ and the oscillations of the two mixer pumps are synchronized such that the flow and sludge erosion patterns on one side of the tank are identical to those on the other side. We simulated the right side of the tank in the AY-102 modeling. Because the AY-102 model predicted that erosion and solids distribution patterns would be very similar for all four solids, predicted vertical solid distributions are presented only for Solid 1. Because Solid 1 consists of 50 vol\% of the total solids, twice the Solid 1 concentration corresponds to the total solids concentration.

\subsection{Pump Jet Mixing of AY-102 Waste with 1,090-Pa Shear Strength}

This case assigned the AY-102 sludge shear strength to be 1,090 $\mathrm{Pa}$, the median value based on the core extrusion observations. The initial condition of the AY-102 model is shown in Figures 3.3 and 3.4. Figure 3.3 is along the 3 o'clock vertical plane (vertical r-z plane, $\mathrm{I}=2$ ), and Figure 3.4 is along the 12 o'clock vertical plane (vertical r-z plane, $\mathrm{I}=14$ ) in the tank. The mixer jets along vertical plane 2 would travel the shortest distance $(15.5 \mathrm{ft}$ or $4.72 \mathrm{~m})$ to reach the tank wall, while the jets along vertical plane 14 (and along the 12 o'clock vertical plane) must travel the longest distance ( $43.5 \mathrm{ft}$ or $13.3 \mathrm{~m}$ ).

Figures 3.3 and 3.4 show the initial 62 -in. (1.58-m) solids layer at the bottom and 186-in. (4.72-m) liquid layer, totaling 248 in. $(6.30 \mathrm{~m})$ of waste in AY-102. It also shows the position of the rotating pump, its withdrawal inlet 6 in. $(0.15 \mathrm{~m})$ above the tank bottom, and a 6-in. $(0.15-\mathrm{m})$ nozzle 15 in. $(038 \mathrm{~m})$ above the tank bottom that injects a $60-\mathrm{ft} / \mathrm{sec}(18.3-\mathrm{m} / \mathrm{s})$ jet into the solids layer. The solid line indicates the tank boundary. The presence of the velocity vector indicates that the area is within the tank.

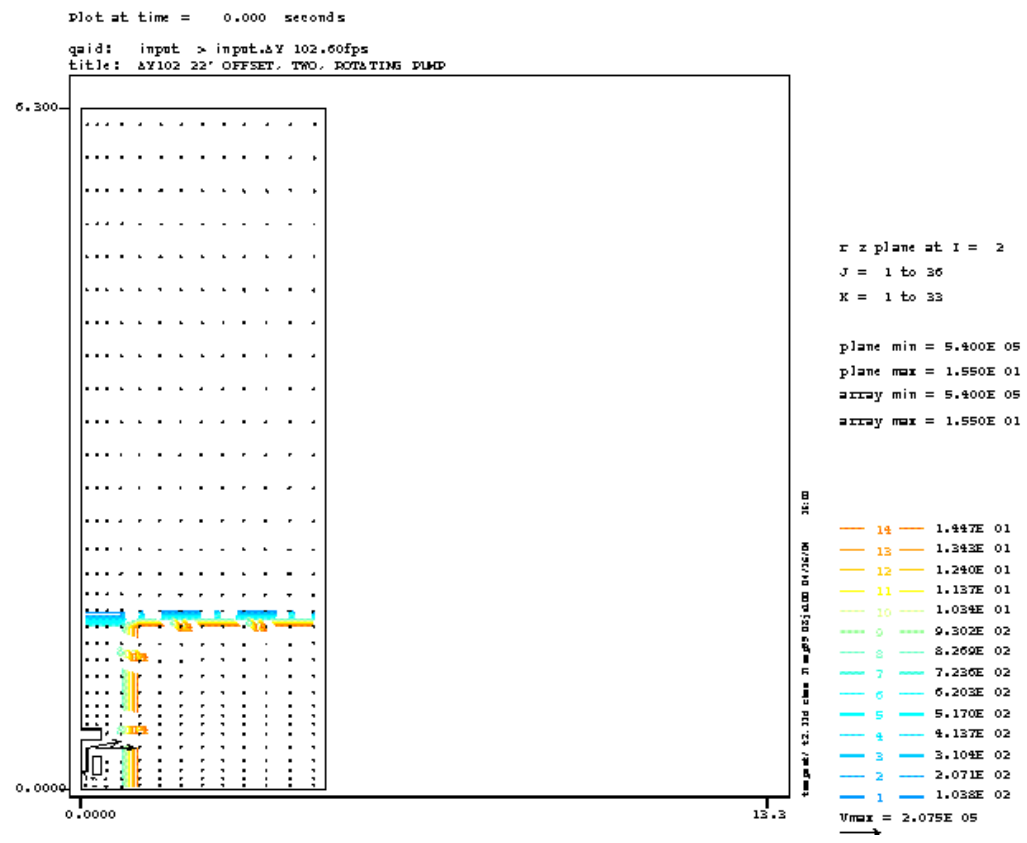

Figure 3.3. Initial AY-102 Waste Condition along 3 O'Clock Position (vertical plane 2) 


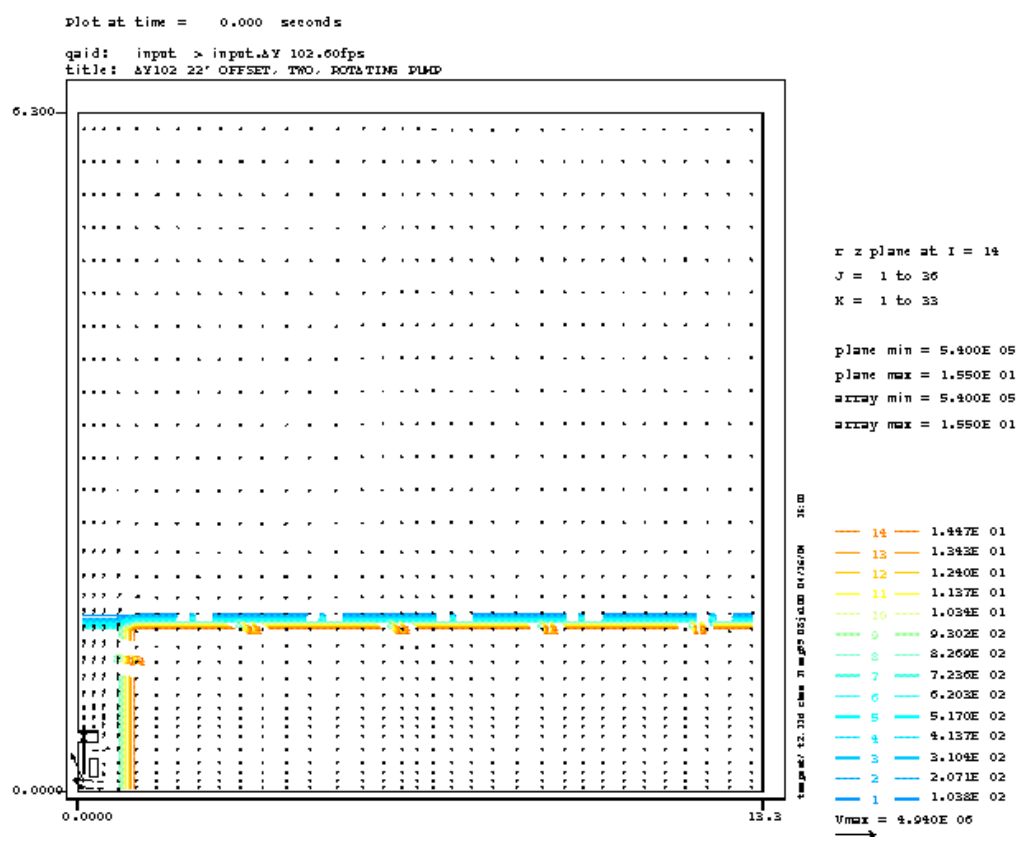

Figure 3.4. Initial AY-102 Waste Condition along 12 O'Clock Position (vertical plane 14)

For example, Figure 3.4 shows the time ( 0 simulation second) and the solids concentration as volume fraction (volume fraction of 1 is $100 \mathrm{vol} \%$ ). The right side of the figure describes which vertical plane is shown (it is the r-z plane, which is vertical plane $14(\mathrm{I}=14)$ oriented at the 12 o'clock position, and an area of plot coverage on these vertical planes (in this case, $\mathrm{J}=1$ to 36 , indicating the entire horizontal direction from the pump center to the tank wall, $13.3 \mathrm{~m}$ away, and $\mathrm{K}=1$ to 33 , indicating the vertical direction from the tank bottom to the waste surface, at $6.3 \mathrm{~m}$ ). The right sides of these plots also show Solid 1 concentrations (expressed in volume fractions) represented by lines 1 through 14. "Plane min" and "plane max" in the figures indicate the minimum and maximum values [solids volume fractions of $5.4 \times 10^{-5}(0.0054 \mathrm{vol} \%)$ and $0.155(15.5 \mathrm{vol} \%)$, respectively, in this case] within the plotted planes, while "array min" and "array max" indicate the minimum and maximum values [solids volume fractions of $5.4 \times 10^{-5}(0.0054 \mathrm{vol} \%)$ and $0.155(15.5 \mathrm{vol} \%)$, respectively, in this case] encountered within the entire tank simulated area. The Solid 1 concentration in the solids (sludge) layer is $15.5 \mathrm{vol} \%$, as shown in the figure. The total solids concentration in the sludge layer is $31 \mathrm{vol} \%$. Solid 1 makes up $50 \mathrm{vol} \%$ of this, as indicated in Table 2.1. The initial solids concentration in the liquid layer was assigned a small value $(0.0054 \mathrm{vol} \%)$ rather than zero to accommodate the settling velocity of the solids for all solids concentrations. As shown, we diluted the solids layer by half in the immediate vicinity of the mixer pumps as the initial condition to reflect the expected waste condition after installing the mixer pump. This dilution also assists in starting up the mixer pumps.

The maximum velocity on the vertical plane is shown at the lower right of the plots (in this case $4.940 \times 10^{-6} \mathrm{~m} / \mathrm{s}$ ) with its corresponding scale lengths. All velocities in this figure are scaled to this magnitude. The jet velocity at the nozzle exit during the pump operation was assigned to be $60 \mathrm{ft} / \mathrm{sec}$ $(18.3 \mathrm{~m} / \mathrm{s})$ during pump operation.

When the mixer pumps began to operate, the initially diluted AY-102 sludge around them was drawn into the pumps and injected back into the sludge layer. At $60 \mathrm{ft} / \mathrm{sec}$, these waste jets exerted enough force to overcome the undiluted sludge with shear strength of 1,090 Pa, burrowing into and diluting it. As the 
jets penetrated and eroded the sludge, each jet spread upward around the end of the penetrated area. The upward-moving jet diluted the sludge above this area. The diluted AY-102 sludge had a reduced shear strength (expressed in Eq. 3.1), which caused the sludge above the jet to collapse and produced rapid mixing with the overlaying supernatant liquid. This diluted waste was then drawn into the mixer pumps and injected back into the collapsing sludge areas, repeating the sludge erosion and mixing processes. The jets eroded the sludge until the forces on the sludge were no longer strong enough to overcome the shear strength.

We simulated the AY-102 pump jet mixing for two simulation hours. By then the jets no longer eroded additional areas of sludge. Figure 3.5 shows where the sludge would remain intact based on the model results (shaded areas). The pump jets mobilized the sludge up to $41 \mathrm{ft}(12.5 \mathrm{~m})$ away; however, the sludge next to the tank wall that is $26 \mathrm{ft}(7.9 \mathrm{~m})$ or more from the mixer pumps was not mobilized due to the tank wall effect. By counting the sludge amount in every computation cell, we estimated that approximately 89 vol\% of the original AY-102 sludge was mobilized by two 300-hp mixer pumps.

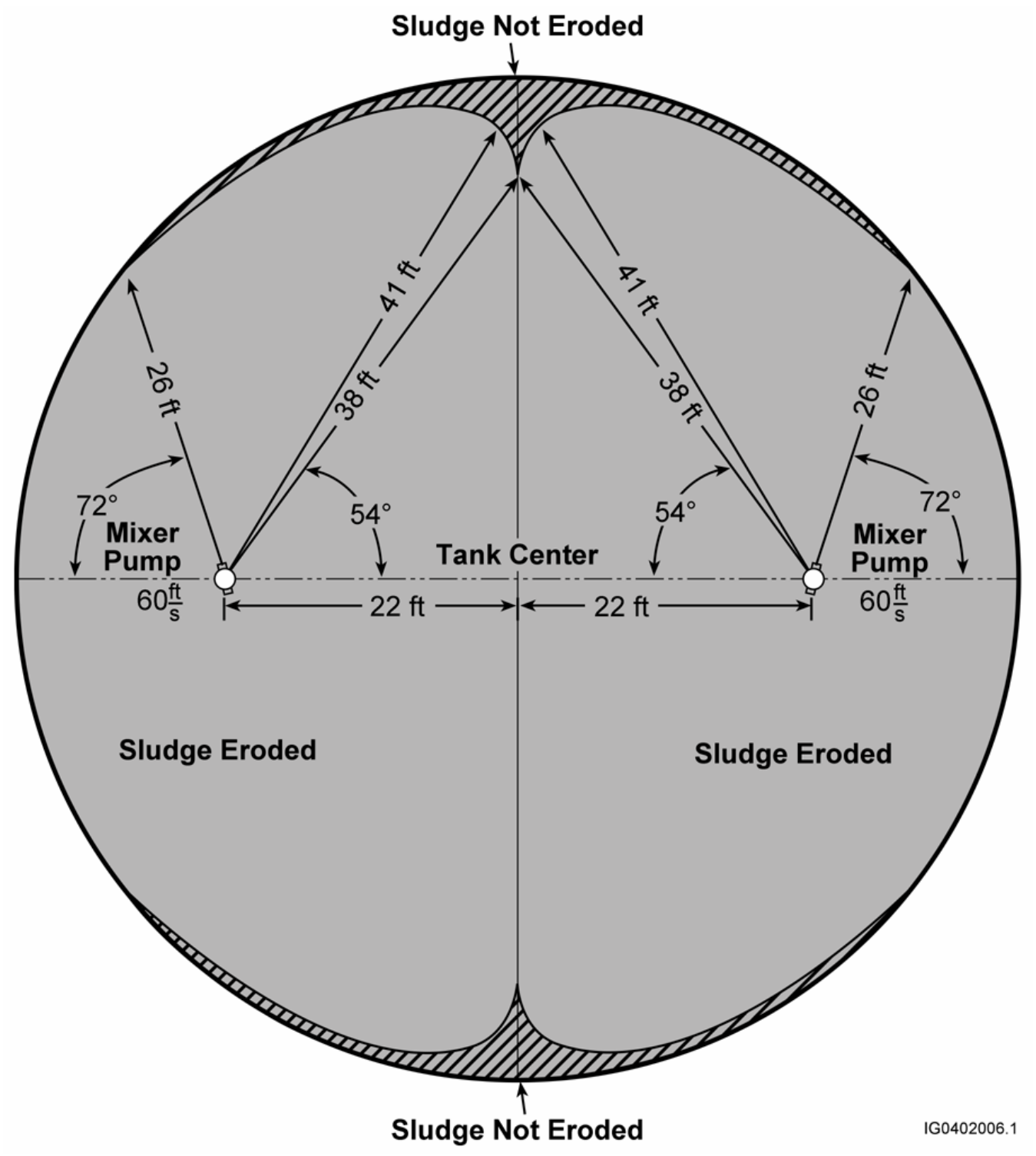

Figure 3.5. Tank Area Eroded by the Two Mixer Pumps for the 1,090-Pa Shear Strength Case 
The two mixer pumps were predicted to mobilize about 89 vol\% of the AY-102 sludge. Additional mixer pumps could only erode up to 7 vol\% more of the initial total sludge volume because the bottom 2.5 -inch sludge layer, making up 4 vol\% of the initial total sludge, would most likely not be mobilized in any case.

Figures 3.6 through 3.9 show vertical slices of the simulation result shown in Figure 3.5. They depict predicted final solids erosion patterns as the jet passes the 3 o'clock (vertical plane 2), 1:40 o'clock (vertical plane 9), 1:25 o'clock (vertical plane 10), and 12 o'clock (vertical plane 14) positions, respectively, in the tank, starting from the mixer pump in the right half of the tank as the center, Note that the last three vertical planes are $75^{\circ}, 85^{\circ}$ and $120^{\circ}$ counter-clockwise from the 3 o'clock position measured from the mixer pump (see Figure 3.5). The jet passes along the 3 and 12 o'clock positions are the shortest and longest, respectively, to the tank wall. In each of these passes, both rotating jets are oriented along the shortest and longest planes to the tank wall at the specific simulation times shown in Figures 3.6 and 3.9. The maximum velocities in the figures represent maximum velocities inside the pump. At the nozzle exit, the jet velocity was $60 \mathrm{ft} / \mathrm{sec}(18.3 \mathrm{~m} / \mathrm{s})$.

Figures 3.6 and 3.7 show that the pump jets eroded all the sludge from the pump to the tank wall out to a radius of $26 \mathrm{ft}(7.9 \mathrm{~m})$, except for the bottom 2.5 inches $(0.06 \mathrm{~m})$ (see also Figure 3.5). The eroded sludge was uniformly distributed in this vertical plane, which shows the Solid 1 concentration as 0.035 volume fraction (3.5 vol\%), corresponding to the total suspended solids concentration of $7 \mathrm{vol} \%$.

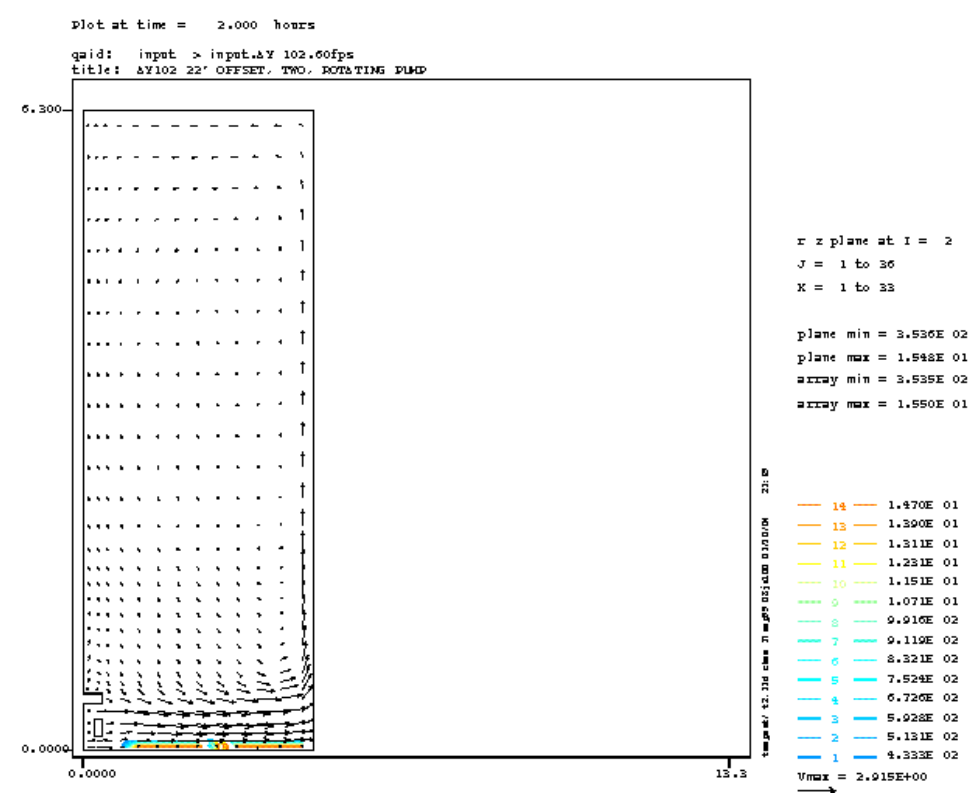

Figure 3.6. Predicted Distributions of Velocity and Sludge Erosion with 1,090-Pa Shear Strength along the Shortest Distance to the Tank Wall (3 o'clock position or vertical plane 2) at 2 Simulation Hours 


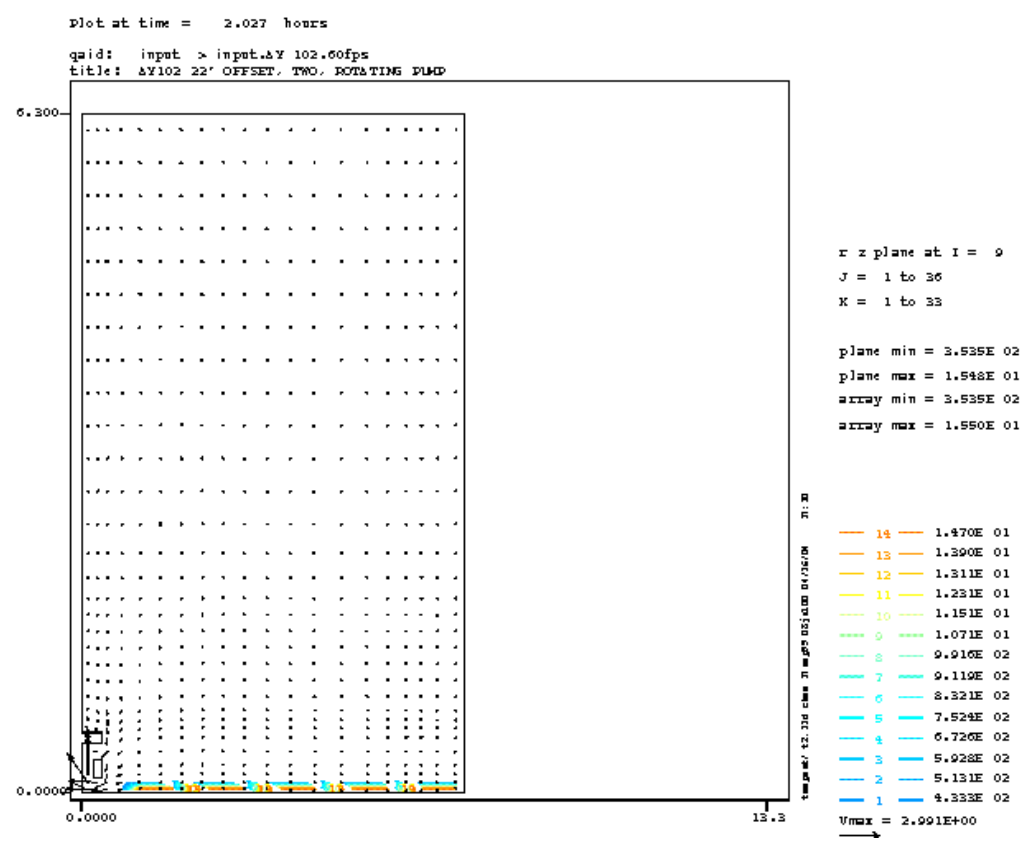

Figure 3.7. Predicted Distributions of Velocity and Sludge Erosion with 1,090-Pa Shear Strength along 1:40 O'Clock Position to Tank Wall (vertical plane 9) at 2 Simulation Hours

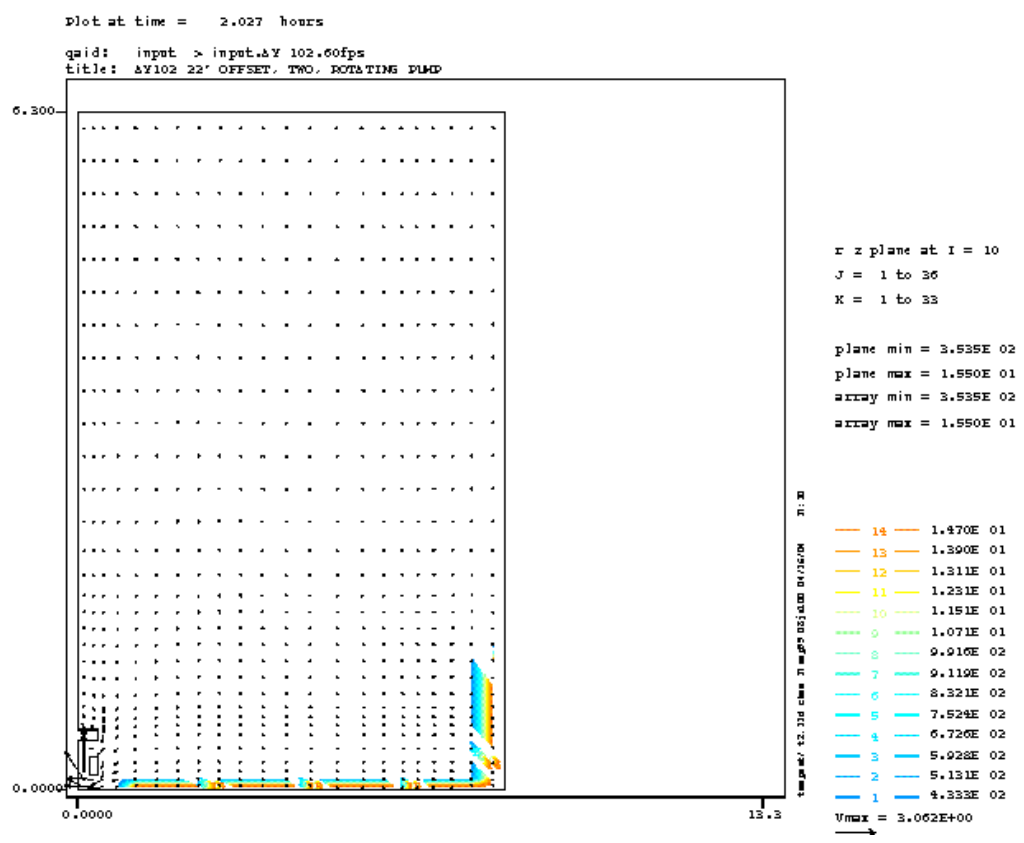

Figure 3.8. Predicted Distributions of Velocity and Sludge Erosion with 1,090-Pa Shear Strength along 12:25 O'Clock Position to the Tank Wall (vertical plane 10) at 2 Simulation Hours 


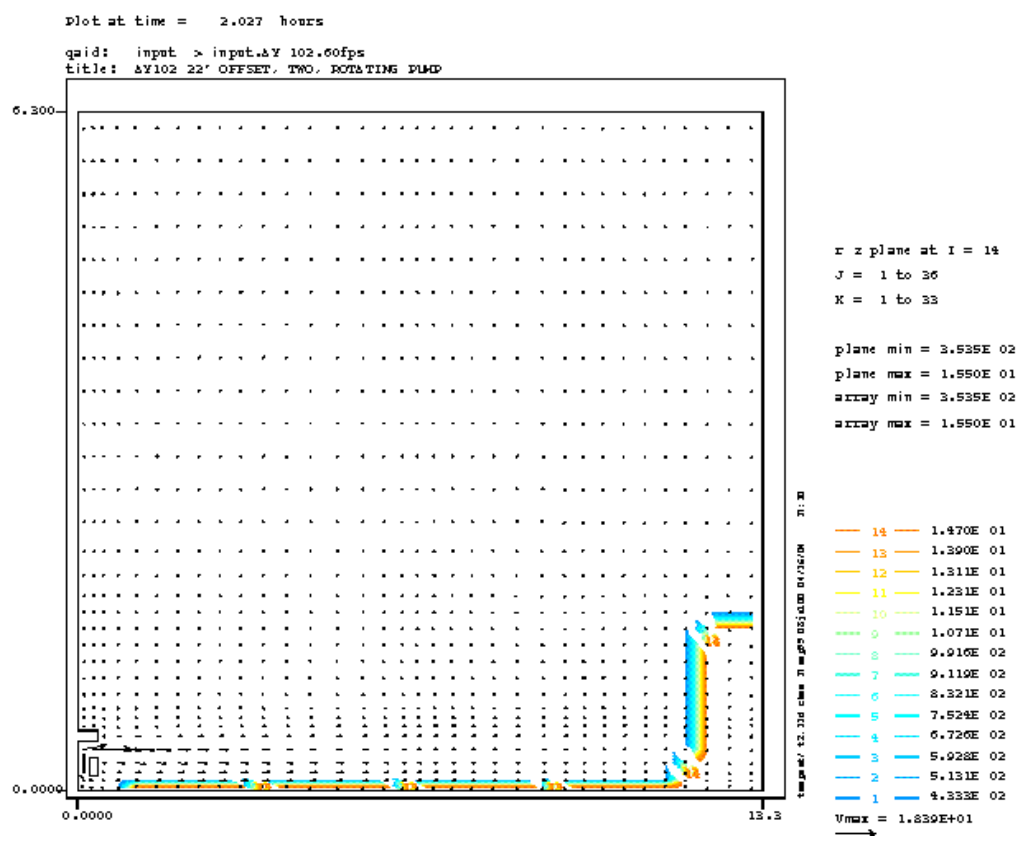

Figure 3.9. Predicted Distributions of Velocity and Sludge Erosion with 1,090-Pa Shear Strength along Longest Distance to Tank Wall (12 o'clock position, or vertical plane 14) at 2 Simulation Hours

However, as shown in Figures 3.5 and 3.8, the pump jets did not mobilize the sludge near the wall that is more than $26 \mathrm{ft}(7.9 \mathrm{~m})$ away from the mixer pumps. Figure 3.9 shows the predicted flow and erosion patterns along the farthest distance to the tank wall $(43.5 \mathrm{ft}$ or $13.3 \mathrm{~m})$. This figure indicates that the jets eroded sludge up to $41 \mathrm{ft}(12.5 \mathrm{~m})$ away. Similar to Figures 3.6 and 3.7, the jets did not erode the bottom 2.5 inches $(0.06 \mathrm{~m})$ of sludge, but did mobilize solids with the Solid 1 concentration of $3.5 \mathrm{vol} \%$ (total solid concentration, $7 \mathrm{vol} \%$ ), and were vertically well mixed. This solids concentration is the same along the shortest distance. Once the sludge was mobilized, the solids were predicted to be uniformly distributed within the tank (within a $1 \%$ concentration variation or $99 \%$ uniformity except within a few inches of the tank bottom).

\subsection{Pump jet Mixing of AY-102 Waste with 2,230-Pa Shear Strength}

This case assigned the AY-102 sludge shear strength as 2,230 $\mathrm{Pa}$, the 97.5 percentile value (based on core extrusion observations) to make a conservative evaluation (more difficult to erode sludge). The initial condition of this case also has an initial 62-in. $(1.58-\mathrm{m})$ solids layer at the bottom and a 186-in. (4.72-m) liquid layer, as shown in Figures 3.3 and 3.4 along the 3 o'clock vertical plane (vertical r-z plane, $\mathrm{I}=2$ ), and along the 12 o'clock vertical plane (vertical r-z plane, $\mathrm{I}=14$ ) in the tank.

Similar to the 1,090 Pa case, we simulated Tank AY-102 until the jets no longer eroded additional areas. Predicted unmobilized tank areas are shown as shaded areas in Figure 3.10, indicating that two mixer pumps would erode the sludge up to $38 \mathrm{ft}(11.6 \mathrm{~m})$ from the pumps. However, due to the tank wall effect, the sludge next to the wall at least $20 \mathrm{ft}(6.1 \mathrm{~m})$ from the mixer pumps would not be mobilized. Again, the bottom 2.5 inches $(0.06-\mathrm{m})$ of sludge would not be eroded. We estimated that approximately 85 vol\% of the original AY-102 sludge would be mobilized by two 300-hp mixer pumps under the 97.5 
percentile shear strength value compared with 89 vol\% for the 1,090-Pa shear strength waste. Thus, the greater the sludge yield strength, the less sludge the mixer pumps mobilized, even through the difference between these two cases is small (see Figures 3.5 and 3.10).

Because two mixer pumps were predicted to mobilize about 85 vol\% of the AY-102 for the 2,230-Pa shear strength case, two additional mixer pumps (total of four) would only erode up to $11 \mathrm{vol} \%$ more of the original sludge while still leaving the bottom 2.5 -inch sludge layer (4 vol\%) intact.

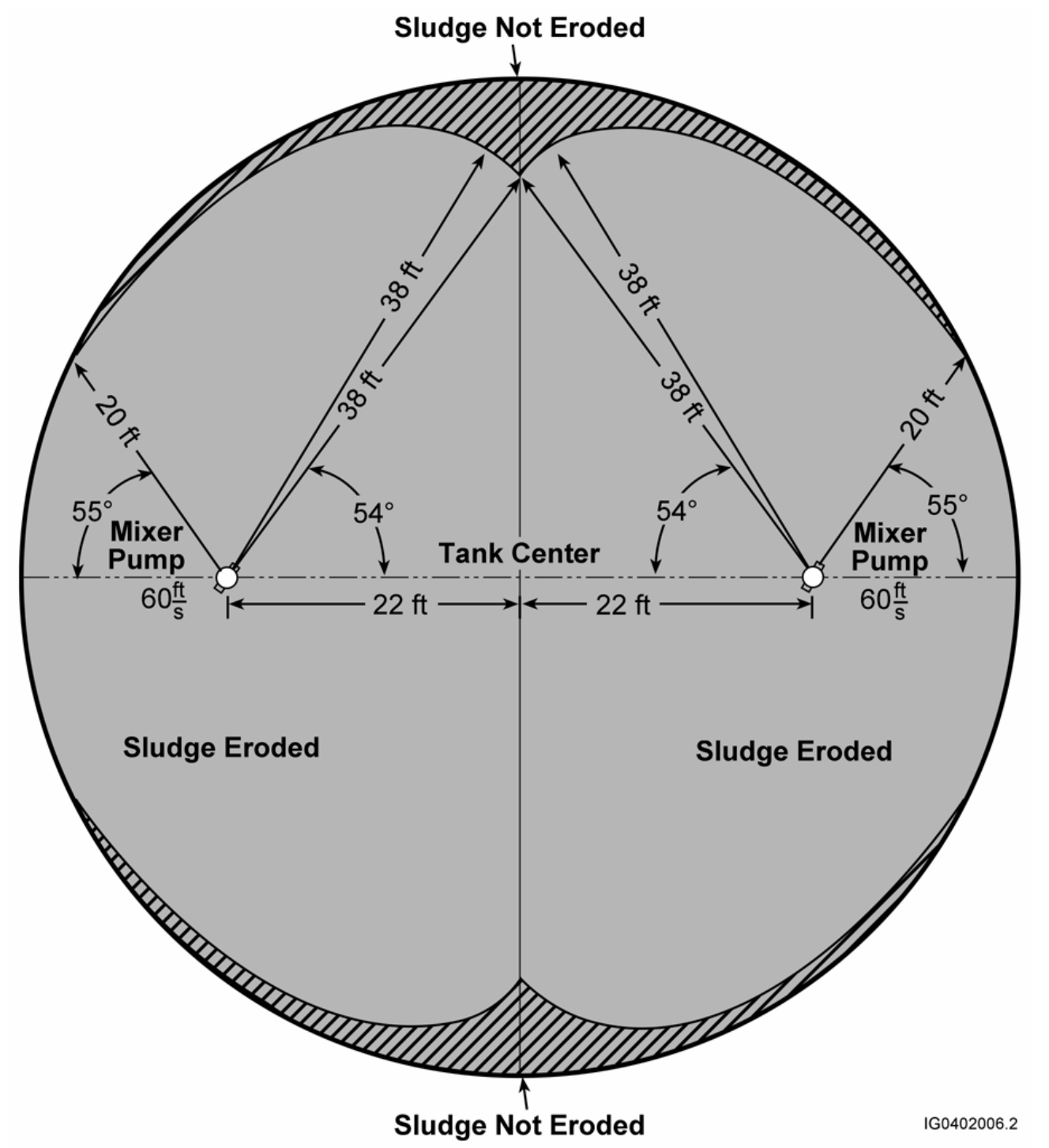

Figure 3.10. Tank Area Eroded by Two Mixer Pumps for the 2,230-Pa Shear Strength Case

The next four figures present vertical slices of the simulation results shown in Figure 3.10. Predicted final solid erosion patterns along the jet passes corresponding to Figures 3.6 through 3.9 are shown in Figures 3.11 through 3.14. These include predicted flow and solids distributions along the shortest and longest distances to the tank wall, shown in Figures 3.11 and 3.14, respectively. Unlike the 1,090-Pa yield strength case (see Figure 3.7), the jets did not erode all the sludge up to the tank wall along the 1:40 


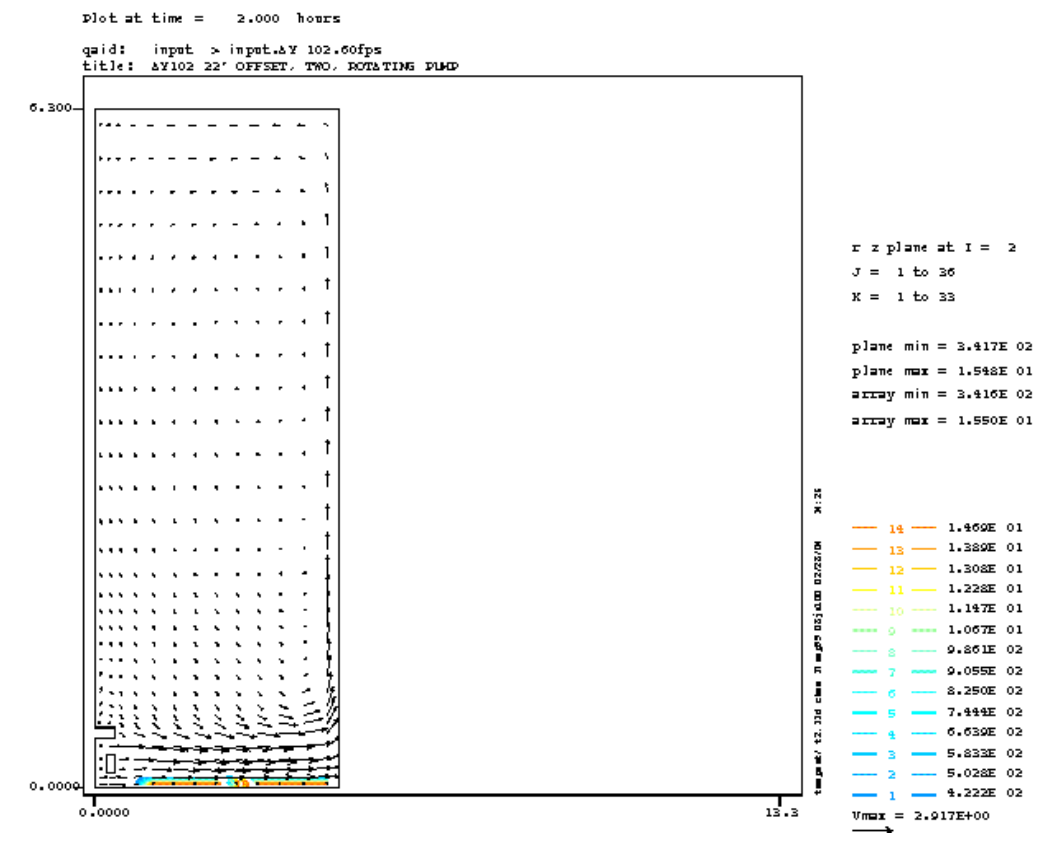

Figure 3.11. Predicted Distributions of Velocity and Sludge Erosion with 2,230-Pa Shear Strength along the Shortest Distance to the Tank Wall (3 o'clock position, or vertical plane 2) at 2 Simulation Hours

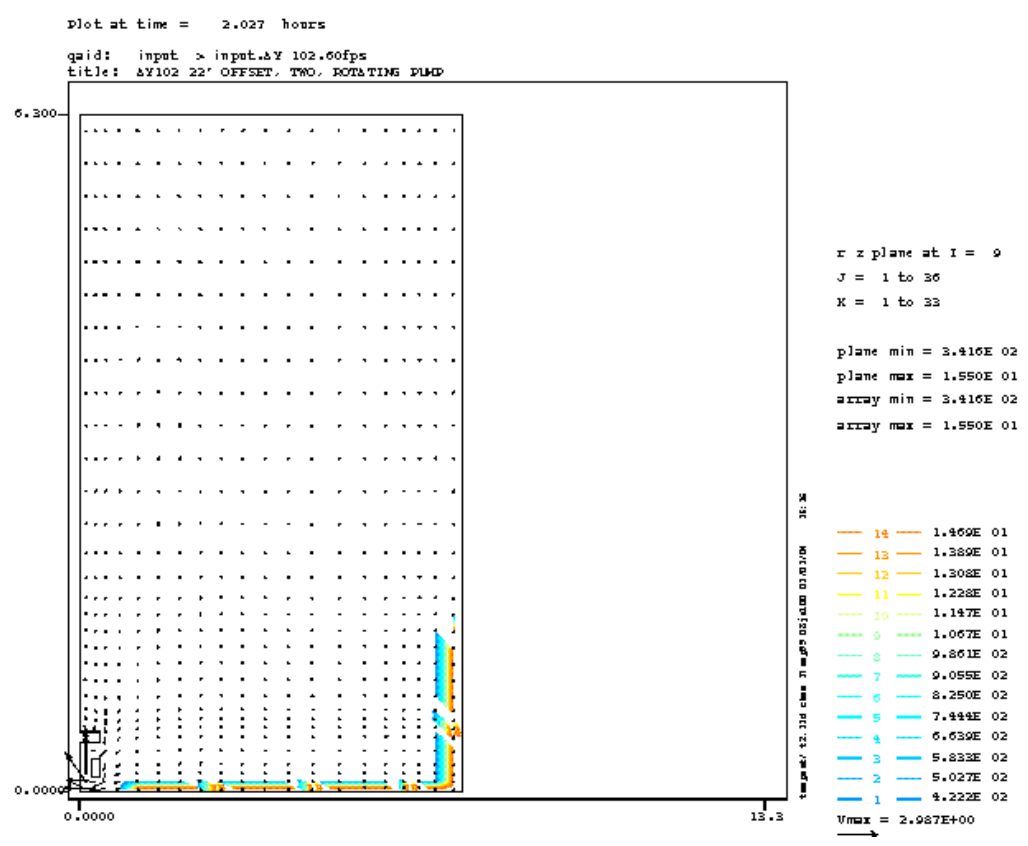

Figure 3.12. Predicted Distributions of Velocity and Sludge Erosion with 2,230-Pa Shear Strength along 1:40 O'Clock Position to Tank Wall (vertical plane 9) at 2 Simulation Hours 


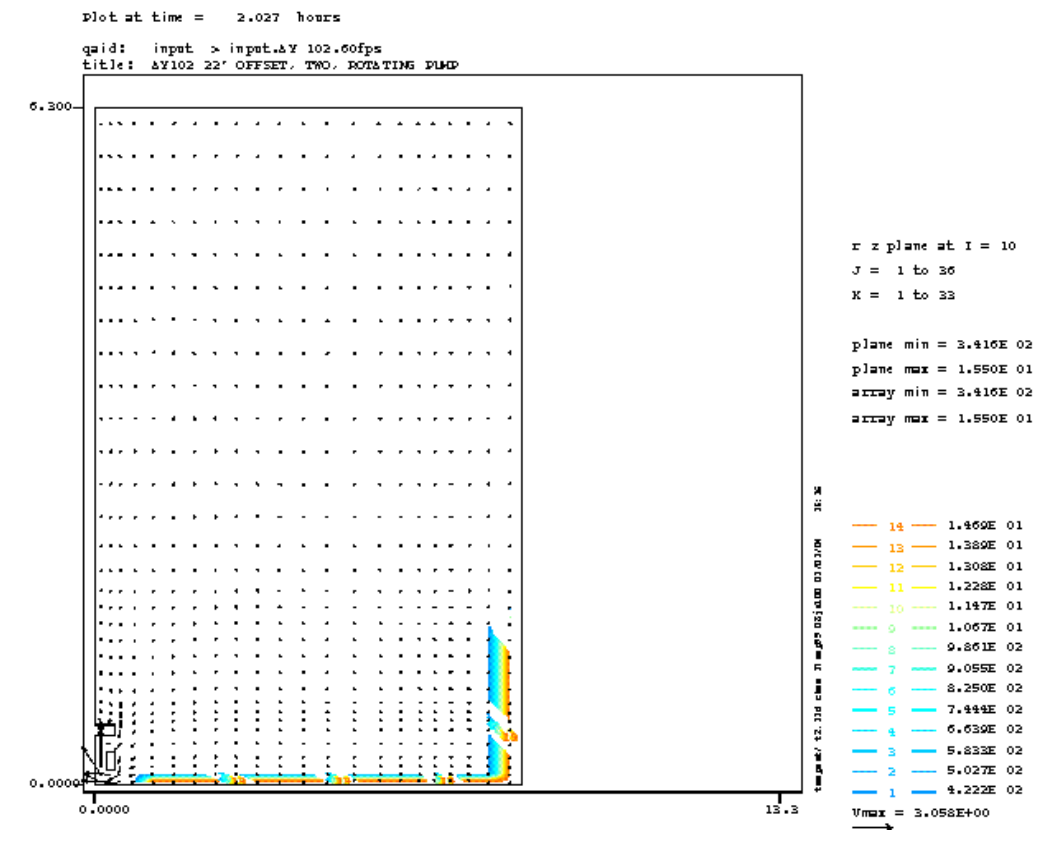

Figure 3.13. Predicted Distributions of Velocity and Sludge Erosion with 2,230-Pa Shear Strength along 1:25 O'Clock Position to Tank Wall (vertical plane 10) at 2 Simulation Hours

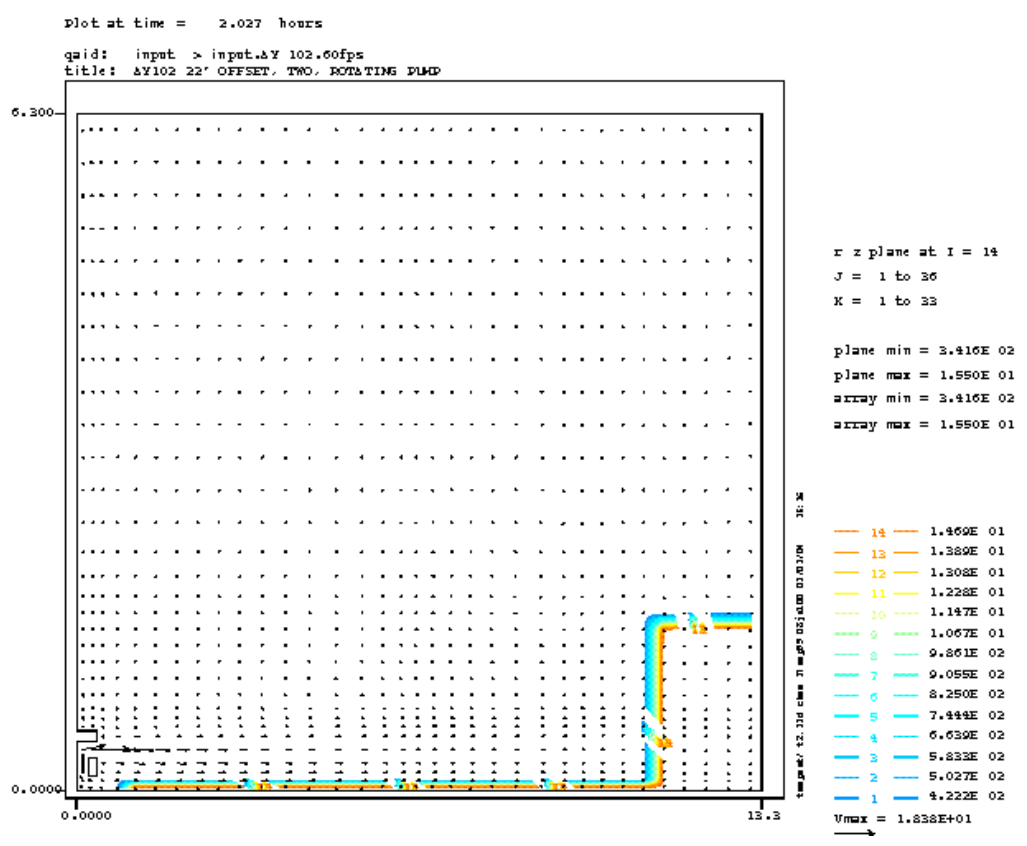

Figure 3.14. Predicted Distributions of Velocity and Sludge Erosion with 2,230-Pa Shear Strength along the Longest Distance to Tank Wall (12 o'clock position, or vertical plane 14) at 2 Simulation Hours 
o'clock position (vertical plane 9), as shown in Figure 3.12. Along the farthest jet pass to the tank wall (43.5 $\mathrm{ft}$ or $13.3 \mathrm{~m}$ away), the jets mobilized the sludge up to $38 \mathrm{ft}(11.6-\mathrm{m})$ from the pump (Figure 3.14). The maximum erosion distance for this case is a little shorter than the maximum distance of $41 \mathrm{ft}(12.5 \mathrm{~m})$ for the 1090-Pa case.

The jets did not erode the bottom 2.5-in. (0.06-m) of sludge, but mobilized solids were vertically well mixed with the Solid 1 concentration of $3.4 \mathrm{vol} \%$ (the total solid concentration of $6.8 \mathrm{vol} \%$ ). Thus the mobilized solids were uniformly distributed within the tank (within a 1\% concentration variation or $99 \%$ uniformity except within few inches above the bottom). 


\subsection{Summary and Conclusions}

The current waste retrieval plan calls for two mixer pumps to mix waste stored in Hanford Tank AY-102. The objective of this evaluation was to determine whether two rotating 300-hp mixer pumps located $22 \mathrm{ft}(6.7 \mathrm{~m})$ from the center of the tank could adequately mix the AY-102 waste. If two mixer pumps were not sufficient to mix the waste, four mixer pumps may be considered.

The tank contains 248 in. $(6.3 \mathrm{~m})$ of HLW consisting of 62 in. $(1.58 \mathrm{~m})$ of sludge and 186 in. (4.72 $\mathrm{m})$ of supernatant liquid. The AY-102 waste properties were determined based on available data and are summarized in Table 4.1. The shear strength was determined using a core extrusion shear strength estimation technique (Rassat et al. 2003) and previously measured shear vane values. The horizontal core extrusion videos for waste cores 270-273, 289, 290 and 300 were used to determine the shear strength values, obtaining a median value of $1,090 \mathrm{~Pa}$, and the $95 \%$ confidence interval is 390 to $2,230 \mathrm{~Pa}$. The shear vane measurements for cores 270-273 indicate the median shear strength is $510 \mathrm{~Pa}$ and $65-6,860 \mathrm{~Pa}$ with the $95 \%$ confidence interval. However, the higher shear strength in this case was the result of outlier measurements with low probability of occurrence. The shear strength values estimated by the AY-102 core extrusion video observation have more data points and were generally greater, more consistent, and more in line with similar Hanford tank wastes than the shear vane values. Thus, we selected the AY-102 shear strength based on the core extrusion observations.

Table 4.1. AY-102 Waste Properties Summary

\begin{tabular}{|l|l|l||}
\hline \multirow{3}{*}{ Liquid } & \multicolumn{1}{|c|}{ Parameter } & \multicolumn{1}{c|}{ Value (units) } \\
\cline { 2 - 3 } & Depth & $186(\mathrm{in})$. \\
\cline { 2 - 3 } & Density & $1,150\left(\mathrm{~kg} / \mathrm{m}^{3}\right)$ \\
\cline { 2 - 3 } & Viscosity & $2.8(\mathrm{Cp})$ \\
\cline { 2 - 3 } & Depth & $62(\mathrm{in})$ \\
\cline { 2 - 3 } & Density & $1,570\left(\mathrm{~kg} / \mathrm{m}^{3}\right)$ \\
\cline { 2 - 3 } & Solids volume fraction & 0.31 \\
\cline { 2 - 3 } & Viscosity & $0.0028 \sim 0.0071(\mathrm{~Pa}-\mathrm{s})$ \\
\cline { 2 - 3 } & Shear strength & $1,090(\mathrm{~Pa}) ;$ median value \\
& & $2,230(\mathrm{~Pa}) ; 97.5$ percentile \\
\hline \multirow{3}{*}{ Undissolved Solids } & Density & $2,500\left(\mathrm{~kg} / \mathrm{m}^{3}\right)$ \\
\cline { 2 - 3 } & Particle size distribution & $2.5 \sim 16.8(\mu \mathrm{m})$ \\
\hline
\end{tabular}

We used the time-varying, three-dimensional, computational fluid dynamics code TEMPEST to simulate the sludge erosion and subsequent mixing of the mobilized sludge and supernatant liquid in Tank AY-102. To evaluate the likely and bounding cases of AY-102 waste mixing, the modeling was performed with a median value of 1,090 $\mathrm{Pa}$ (likely condition) and a conservative (more difficult to erode) 97.5 percentile value of 2,230 $\mathrm{Pa}$ for shear strength.

According to the AY-102 model, the two rotating mixer pumps would erode $89 \mathrm{vol} \%$ of the sludge with a shear strength of $1,090 \mathrm{~Pa}$. They would erode sludge up to $41 \mathrm{ft}(12.5 \mathrm{~m})$ from the off-center mixer pumps, but the bottom 2.5 in. $(0.06 \mathrm{~m})$ of sludge would remain. Due to the wall effect, the sludge at the tank wall that is more than $26 \mathrm{ft}(7.9 \mathrm{~m})$ from the mixer pumps also would not be mobilized. 
Once the sludge is mobilized, the solids were predicted to be uniformly suspended in the tank within a $1-\mathrm{vol} \%$ concentration variation ( $99 \%$ uniformity) except within few inches of the bottom. The two mixer pumps were predicted to mobilize about 89 vol\% of the AY-102 waste. Two additional mixer pumps would erode only up to 7 vol\% more sludge because the bottom 2.5 -inch sludge layer makes up about 4 vol $\%$ of the initial total sludge volume and would most likely not be mobilized.

With a shear strength of $2,230 \mathrm{~Pa}$, the two pumps would erode $85 \mathrm{vol} \%$ of the sludge, slightly less than $89 \mathrm{vol} \%$ for the $1,090 \mathrm{~Pa}$ shear strength case. With a yield strength of 2,230 $\mathrm{Pa}$, the pump jets mobilized the sludge up to $38 \mathrm{ft}(11.6 \mathrm{~m})$ from the pumps, except the bottom $2.5 \mathrm{in}$. $(0.06 \mathrm{~m})$ sludge layer. The sludge at the tank wall, which is more than $20 \mathrm{ft}(6.1 \mathrm{~m})$ away from the mixer pumps, would also not be mobilized due to the tank wall effect. These results indicate that the greater the sludge shear strength, the less the mixer pumps can erode, although the differences between the 1,090 and 2,230 Pa cases in the amount of erosion and the maximum erosion distance from the pumps are not very large. Similar to the 1,090 $\mathrm{Pa}$ case, the solids were predicted to be uniformly suspended within the tank within a 1-vol\% concentration variation (99\% uniformity) except within 2.5 inches of the bottom.

Because the two mixer pumps were predicted to mobilize about $85 \mathrm{vol} \%$ of the AY-102 sludge having a 2,230 Pa shear strength, additional mixer pumps would only erode up to $11 \mathrm{vol} \%$ more of the original sludge, while expecting to leave the bottom 2.5 inches intact. 


\subsection{References}

Barker SA and DC Hedengren. 2003. Methodology and Calculations for the Assignment of Waste Groups for the Large Underground Waste Storage Tanks at then Hanford Site. RPP-10006 Rev. 2A, CH2M HILL Hanford Group, Inc., Richland, WA.

Barker SA and AR Lechelt. 2000. Determination of Waste Groupings for Safety Analyses. RPP-6171 Rev. 0, CH2M HILL Hanford Group, Inc., Richland, WA.

Bechtold DB, L Jensen, JB Duncan, WS Callaway III, GA Cooke, DL Herting, JC Person, JR Jewett, and JM Tingey. 2002. Particle Property Analyses of High-Level Waste Tank Sludges. HNF-8862 Rev. 0, Fluor Hanford Inc., Richland, WA.

Ellwood KR, JGC Georgiou, TC Papanastasiou, and JO Wilkes. 1990. "Laminar Jets of Bingham Plastic Liquids." J. of Rheology 34(6):787-812.

Gauglitz PA and JT Aikin. 1997. Waste Behavior During Horizontal Extrusion: Effect of Waste Strength for Bentonite and Kaolin/Ludox Simulants and Strength Estimates for Wastes from Hanford Tanks 241SY-103, AW-101, AN-103, and S-102. PNNL-11706, Pacific Northwest National Laboratory, Richland, WA.

Heath WO. 1987. Development of an In Situ Method to Define the Rheological Properties of Slurries and Sludges Stored in Underground Tanks. PNL-6083, Pacific Northwest National Laboratory, Richland, WA.

Herting DL. 1998. Results of Dilution Studies with Waste from Tank 241-AN-104. HNF-3352 Rev. 0, Numatec Hanford Corporation, Richland, WA.

Herting DL. 1999. Results of Dilution Studies with Waste from Tank 241-AW-101. HNF-4964 Rev. 0, Numatec Hanford Corporation, Richland, WA.

Jewett JR, SD Estey, L Jensen, NW Kirch, DA Reynolds, and Y Onishi. 2002. Values of Particle Size, Density, and Slurry Viscosity to Use in Waste Feed Delivery Transfer System Analysis. RPP-9805, U.S. Department of Energy Office of River Protection, Richland, WA.

Onishi Y, BE Wells, SA Hartley, and SK Cooley. 2002. Pipeline Cross-Site Transfer Assessment for Tank 241-SY-101. PNNL-13650, Pacific Northwest Laboratory, Richland, WA.

Onishi Y and DS Trent. March 1999. "Mobilization Modeling of Erosion-Resisting Radioactive Tank Waste." Proceedings of the Rheology in the Mineral Industry II, Kahuku, Hawaii. United Engineering Foundation, New York, pp. 45-56.

Rassat SD, LA Mahoney, BE Wells, DP Mendoza, and DD Caldwell. 2003. Assessment of Physical Properties of Transuranic Waste in Hanford Single-Shell Tanks. PNNL-14221, Pacific Northwest National Laboratory, Richland, WA. 
Reynolds DA. 1992. Tank 101-SY Window C Core Sample Results and Interpretation. WHC-EP-0589, Westinghouse Hanford Company, Richland, WA.

Stewart CW, JM Alzheimer, ME Brewster, G Chen, RE Mendoza, HC Reid, GL Shepard, and G Terrones. 1996. In Situ Rheology and Gas Volume in Hanford Double-Shell Waste Tanks. PNNL11296, Pacific Northwest Laboratory, Richland, WA.

TWINS. The Tank Waste Information System database. Created for DOE by Pacific Northwest National Laboratory. http://twins.pnl.gov/twins3/twins.htm.

Urie MW, PR Bredt, JA Campbell, OT Farmer, SK Fiskum, LR Greenwood, EW Hoppe, LK Jagoda, GM Mong, AP Poloski, RD Scheele, CZ Soderquist, RG Swoboda, MP Thomas, and JJ Wagner. 2002. Chemical Analysis and Physical Property Testing of 241-AZ-101 Tank Waste - Supernatant and Centrifuged Solids. PNWD-3215, Battelle - Pacific Northwest Division, Richland, WA.

Warrant RW. 2001. Results of Retrieval Testing of Sludge from Tank 241-AY-102. RPP-8909 Rev. 0, Fluor Hanford Inc., Richland, WA. 


\section{Distribution}

No. of

Copies

\section{Onsite}

3 DOE Office of River Protection

J. Navarto

2 Numatec Hanford Company

SR Briggs

CA Rieck

2 CH2M HILL Hanford Group

JE Van Beek

EW Martinen
No. of

Copies

31 Pacific Northwest National Laboratory

GH Beeman

K9-09

SQ Bennett

K7-90

TM Brouns

K9-09

DE Kurath

P7-28

TE Michener

K7-15

K7-15

K9-09

WC Weimer

K7-15

BE Wells (3)

K1-06 